Xu, J., R. J. Lowe, G. N. Ivey, C. Pattiaratchi, N. L. Jones, and R. Brinkman (2013), Dynamics of the summer shelf circulation and transient upwelling off Ningaloo Reef, Western Australia, J. Geophys. Res. Oceans, 118, 1099-1125, 10.1002/igrc.20098.

(C)2013. American Geophysical Union. All Rights Reserved.

This is the final published version of the article accepted for publication in Journal of Geophysical Research: Oceans, following peer review. The definitive published version (see citation above) is located on the article abstract page of the publisher, Oxford University Press

This version was made available in the UWA Research Repository on 28 October 2014 in compliance with the publisher's policies on archiving in institutional repositories.

Use of the article is subject to copyright law. 


\title{
Dynamics of the summer shelf circulation and transient upwelling off Ningaloo Reef, Western Australia
}

\author{
Jiangtao Xu, ${ }^{1}$ Ryan J. Lowe, ${ }^{2}$ Gregory N. Ivey, ${ }^{1}$ Charitha Pattiaratchi, ${ }^{1,3}$ \\ Nicole L. Jones, ${ }^{1,3}$ and Richard Brinkman ${ }^{4}$ \\ Received 19 July 2012; revised 21 January 2013; accepted 25 January 2013; published 11 March 2013.
}

[1] The shelf circulation off Ningaloo Reef near the North West Cape of Western Australia is driven by complex interactions between the southward flowing Leeuwin Current and wind-driven currents that episodically reverse the coastal flow toward the north. The presence of these northward (equatorward) wind-driven currents is thought to make this section of coast one of the few locations along Western Australia to experience periodic coastal upwelling. We used a combination of field observations and numerical modeling to investigate the summer circulation and upwelling dynamics along Ningaloo Reef. We analyzed current and temperature profiles from moorings at four sites across the shelf and used two Regional Ocean Modeling System (ROMS) sub-models: (1) a coarser model of northwestern Australia forced by a global ocean model and (2) a nested fine-scale model of the Ningaloo region. This nesting significantly improved model skill as it included the offshore mesoscale dynamics that strongly influenced the shelf circulation off Ningaloo. The field observations revealed several northward flow reversals, accompanied by cooling of the coastal waters adjacent to Ningaloo, which were associated with strong northward wind events. Analysis of the coastal heat budget revealed that cooling events were primarily driven by upwelling, whereas warming of coastal waters during relaxation events resulted mostly from along-shelf advection of warm water from the north. Due to the combined effects of its relatively steep ( $\sim 1 / 50$ slope) shelf and strong summer stratification, upwelled water was sourced from the interior of the water column, likely influencing the sources and fluxes of nutrients to Ningaloo Reef.

Citation: Xu, J., R. J. Lowe, G. N. Ivey, C. Pattiaratchi, N. L. Jones, and R. Brinkman (2013), Dynamics of the summer shelf circulation and transient upwelling off Ningaloo Reef, Western Australia, J. Geophys. Res. Oceans, 118, 1099-1125, doi:10.1002/jgrc.20098.

\section{Introduction}

[2] Ningaloo Reef, extending $\sim 300 \mathrm{~km}$ south from the North West Cape of Western Australia $\left(\sim 22^{\circ} \mathrm{S}\right)$ is Australia's longest fringing reef system (located within $3 \mathrm{~km}$ from shore) and a United Nations World Heritage site, containing a large range of habitats with a high diversity of marine communities (Figure 1). The unique oceanography of this continental shelf region is thought to be critical in driving its higher rates of pelagic production compared to most other sections of

\footnotetext{
${ }^{1}$ School of Environmental Systems Engineering, University of Western Australia, Crawley, Australia.

${ }^{2}$ School of Earth and Environment, University of Western Australia, Crawley, Australia.

${ }^{3}$ The UWA Oceans Institute, University of Western Australia, Crawley, Australia.

${ }^{4}$ Australian Institute of Marine Science, Townsville, Queensland, Australia.

Corresponding author: J. Xu, School of Environmental Systems Engineering, University of Western Australia, Crawley, Australia. (xu@sese.uwa.edu.au)

(C)2013. American Geophysical Union. All Rights Reserved. 2169-9275/13/10.1002/jgrc.20098
}

Western Australia [Hanson et al. 2005; Rousseaux et al. 2012], which ultimately supplies a nutrient source to support the high productivity of shallow inshore coral reef communities [Wyatt et al. 2010].

[3] Unlike the dominant current systems along the eastern margins of most ocean basins globally, the eastern boundary current system along the broad $\sim 1500 \mathrm{~km}$ long west coast of Australia $\left(\sim 22^{\circ}\right.$ to $\left.\sim 35^{\circ} \mathrm{S}\right)$ operates much differently, with the shelf flow generally dominated year-round by the poleward-flowing Leeuwin Current (LC) that opposes the equatorward wind stresses [Church et al., 1989; Cresswell and Peterson, 1993; Smith et al., 1991] (Figure 1). The LC is a shallow $(<300 \mathrm{~m}$ deep) and narrow $(<100 \mathrm{~km}$ wide) current that flows strongest between May and August and has a core located near the shelf break with a maximum surface velocity of $\sim 0.5 \mathrm{~m} \mathrm{~s}^{-1}$ It consists of warm, lowsalinity water originating from the Pacific Ocean, which is advected through the Indonesian Archipelago into the Indian Ocean [Cresswell and Golding, 1980; Godfrey and Ridgway, 1985]. Studies have shown that the LC is driven by a strong and persistent geopotential gradient along Western Australia, which is typically more than $2 \times 10^{-6} \mathrm{~m} \mathrm{~s}^{-2}$ [Gersbach et al., 1999; Godfrey and Ridgway, 1985; 


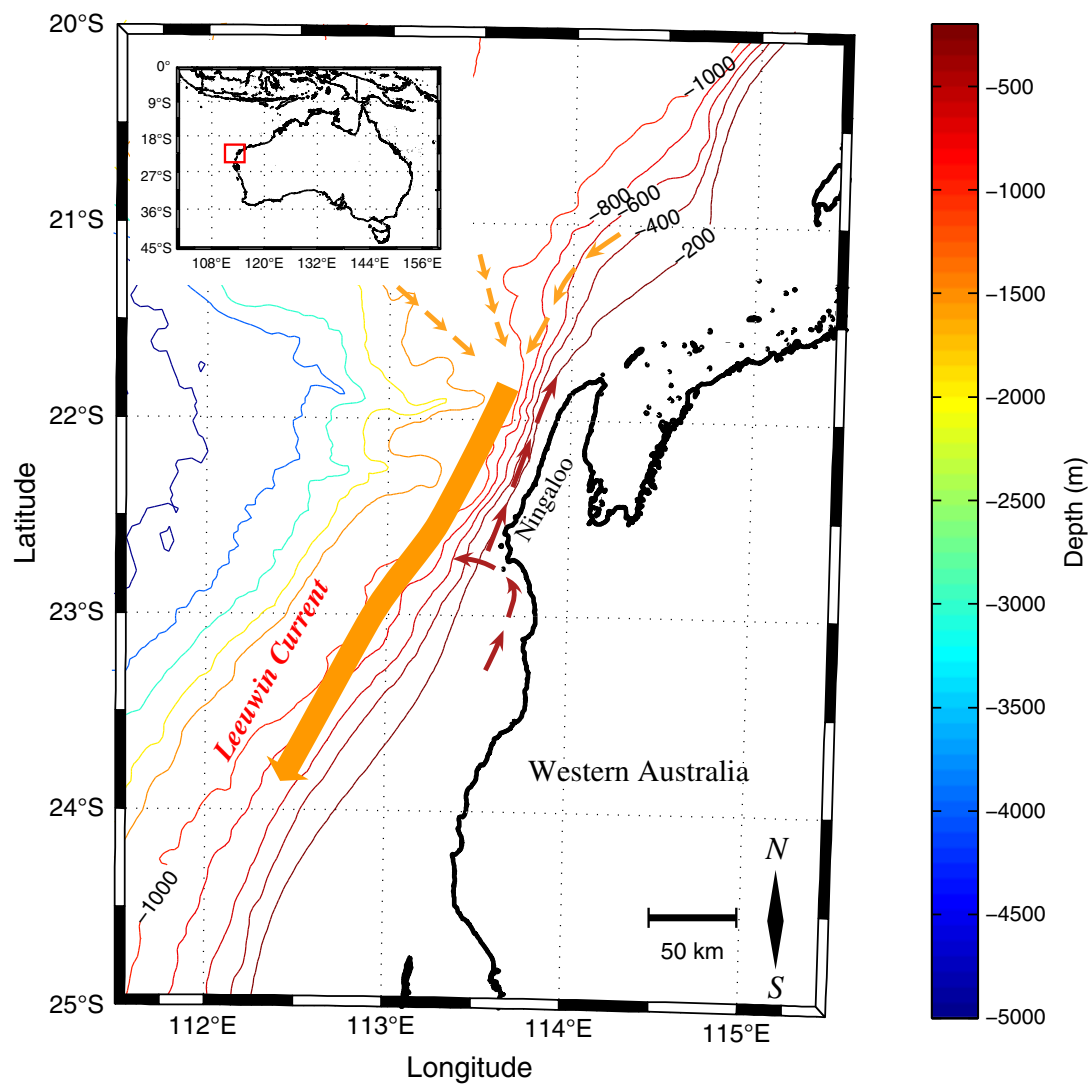

Figure 1. Bathymetry of the continental shelf region around Ningaloo Peninsula shown with a schematic of historically assumed shelf circulation patterns superimposed. The small red arrows near-shore indicate a wind-driven northward coastal current that is assumed to be present on the shelf in summer.

Smith et al., 1991; Thompson, 1987], roughly an order of magnitude greater than typical values for other eastern boundary current systems, e.g., around $2 \times 10^{-7} \mathrm{~m} \mathrm{~s}^{-2}$ off Peru [Mesias et al., 2003] and around $5 \times 10^{-7} \mathrm{~m} \mathrm{~s}^{-2}$ off California [Zamudio and Lopez, 1994]. As a result, this anomalously strong geopotential gradient and the associated LC tend to suppress persistent upwelling along the entire Western Australian coast despite the presence of strong upwellingfavorable winds.

[4] However, some historical observations along Western Australia have shown that during summer, cold water suggestive of upwelling can episodically be present at discrete locations along the continental shelf, in particular between Cape Leeuwin and Cape Naturaliste in the southwest $\left(\sim 34^{\circ} \mathrm{S}\right)$ [Gersbach et al., 1999] and in the northwest region adjacent to Ningaloo Reef [Simpson and Masini, 1986; Taylor and Pearce, 1999; Wilson et al., 2002], specifically between the North West Cape in the north and Point Cloates in the south (a region hereinafter referred to as the "Ningaloo Peninsula") (Figure 1). Off the Ningaloo Peninsula, historical satellite sea surface temperature (SST) images have revealed cooler surface water appearing occasionally on the shelf during summer, which has been proposed to be due to upwelling [Taylor and Pearce, 1999]. Limited ship-based observations have shown more direct evidence of upwelling through cross-shelf temperature and salinity transects obtained off the Ningaloo Peninsula [Hanson et al., 2005; Woo et al., 2006]. Some idealized numerical modeling results have also predicted that a northward current can form adjacent to this region during periods of strong northward winds [Woo et al., 2006] (e.g., in Figure 1), but how these flows are associated with upwelling was not investigated. These studies have suggested that the prevailing equatorward wind stresses may occasionally be strong enough to locally overcome the poleward along-shelf flow driven by the geopotential gradient, thus reversing the shelf circulation and potentially leading to coastal upwelling along the Ningaloo Peninsula. With the historical focus on either satellite sea surface temperature data or snapshots of hydrographic conditions from individual shipbased transects, this limited prior work has never directly quantified the importance of coastal upwelling to this region.

[5] Globally, detailed process-based studies of transient upwelling in the presence of counteracting dynamics (e.g., along-shelf pressure gradients) are comparatively limited when compared to the more abundant literature focusing on systems with more persistent coastal upwelling [e.g., Allen, 1980; Allen and Smith, 1981; Allen et al., 1995; Fewings and Lentz, 2010]. Nevertheless, transient poleward flows during episodes of wind relaxation have been investigated, for example, along the persistently upwelling central California coast where the dominant equatorward winddriven coastal flow can sometimes be reversed by the along-shelf pressure gradient when local wind stresses relax [e.g., Allen and Smith, 1981; Melton et al., 2009]. Analytical theories and idealized numerical modeling have also been developed and applied to investigate the general momentum balances associated with coastal upwelling, as influenced by a combination of a counteracting wind stress, 
along-shelf pressure gradient and nonlinear momentum divergence [e.g., Lentz and Chapman 2004]. Other studies have investigated the importance of an onshore geostrophic flow (due to an along-shelf pressure gradient) to coastal upwelling; for example, recent work focusing on New Caledonia's barrier reef system that suggested these flows significantly limited the cross-shelf Ekman transport [Marchesiello and Estrade, 2010]. Finally, a number of studies have examined the heat budget in coastal upwelling zones by studying the role of heat advection and air-sea heat transfer in upwelling and relaxation events [Dever and Lentz, 1994; Gan and Allen, 2002; Richman and Badan-Dangon, 1983].

[6] Recent long-term measurements at Ningaloo have now indicated that long duration ( $>1$ week) wind-driven equatorward flows are rarely observed on the shelf during any season of the year [Lowe et al., 2012]. Thus, while wind-driven equatorward currents do sporadically occur off the Ningaloo coast, the complex interactions between the local wind forcing, the persistent poleward pressure gradient, the transient mesoscale features in the region, the influence of the shelf topography, and seasonal stratification still remain poorly understood. This paper investigates these dynamics, with a specific focus on the processes occurring during the austral summer period when the equatorward wind stresses are historically at their maximum and hence transient upwelling is thought to most likely to occur. The paper is structured such that we first describe results from a 2 month field experiment and examine the dynamics revealed by the observations. We then present and evaluate a nested numerical model of the region using ROMS and evaluate the model's sensitivity to both local wind forcing and the large-scale forcing imposed by a global-scale ocean model (HYCOM). Finally, we describe the application of the model to investigate the dynamics of transient upwelling along this coast, the dominant momentum balances established both along and across the shelf, and the processes controlling temperature fluctuations within the coastal region through a heat budget analysis.

\section{Methodology}

\subsection{Site Description and Climatology}

[7] The study area is located along the northwest coast of Australia and contains the United Nations World Heritage Ningaloo Reef, Australia’s largest ( $300 \mathrm{~km}$ long) fringing coral reef system. The study specifically focused on a $\sim 100 \mathrm{~km}$ relatively straight section of coastline between the North West (NW) Cape in the north and Point Cloates in the south (termed the "Ningaloo Peninsula"). The bathymetry of this region is characterized by a relatively steep $(\sim 1: 50)$ continental shelf slope. Along-shelf bathymetry variations adjacent to the Ningaloo Peninsula are relatively small; i.e., the $200 \mathrm{~m}$ isobath (shelf break) runs parallel to shore and is consistently located within $10 \mathrm{~km}$ of the coast. The continental shelf gradually widens both north of the NW Cape and south of Point Cloates (Figure 1).

[8] The winds along the Ningaloo Peninsula display strong seasonal variability. During spring and early-summer months (October to January), relatively strong winds from the southwest (upwelling-favorable) dominate with speeds averaging $\sim 6 \mathrm{~m} \mathrm{~s}^{-1}$, while during autumn and winter (April to August), the winds become variable in both speed and direction [Lowe et al., 2012]. The area experiences a mixed, dominantly semi-diurnal tide with a mean tidal range of only $\sim 0.8 \mathrm{~m}$ [Taebi et al., 2011] and typical tidal velocities of less than $0.1 \mathrm{~m} \mathrm{~s}^{-1}$. The local inertial period along the Ningaloo Peninsula varies with latitude between 29 and $32 \mathrm{~h}$.

[9] There does not appear to be a well-defined LC north of Ningaloo Reef, while south of the NW Cape the persistent along-shelf pressure gradient is associated with an along-shelf flow (LC) that accelerates southward down the coast [Godfrey and Ridgway, 1985; Smith et al., 1991]. The strength of the LC varies throughout the year due to seasonal variability in large-scale wind forcing and possibly the along-shelf geopotential gradient [Feng et al., 2003]. The surface mixed layer off the coast of Ningaloo is highly variable, ranging from less than $50 \mathrm{~m}$ in summer to as deep as $140 \mathrm{~m}$ during winter, largely due to seasonal variability in regional surface net heat fluxes [Lowe et al., 2012; Rousseaux et al., 2012].

\subsection{Field Measurements}

[10] We conducted a 2 month field experiment during the austral summer between 10 November 2009 and 3 January 2010. This included an array of four instrument moorings deployed in a cross-shelf transect off the coast of Tantabiddi, located $\sim 20 \mathrm{~km}$ south of the NW Cape (Figure 2 and Table 1). These were located on the $\sim 50 \mathrm{~m}, 75 \mathrm{~m}, 100 \mathrm{~m}$, and $150 \mathrm{~m}$ isobaths (hereinafter referred to as sites M2 through M5, respectively). Note that mooring M1 was located inside the shallow Ningaloo Reef lagoon and hence is not discussed in the present study. The shelf moorings included a bottommounted ( 4-7 m above bed) acoustic Doppler current profiler (ADCP, Teledyne RD Instruments), which measured three-dimensional current profiles, as well as an array of temperature sensors (SBE39s, Seabird Electronics) to record the vertical temperature structure of the water column (Table 1). Of the four offshore moorings, the spacing of the SBE39s was most concentrated at M3 and M5, where the vertical resolution was typically $<10 \mathrm{~m}$. The mooring lines also included SBE39s with pressure sensors close to the surface to correct for possible mooring deflection in response to the currents. During the experiment, all instruments collected data for the duration of the experiment, except at M5 where the ADCP failed after $\sim 3$ weeks on 23 November. Local wind conditions (speed $U_{10}$ and direction measured $10 \mathrm{~m}$ above sea level) were recorded continuously at the Australian Institute of Marine Science Milyering weather station, located on the coast $\sim 15 \mathrm{~km}$ south of Tantabiddi (Figure 2a). Additionally, cross-shelf transects of temperature and salinity were obtained from CTD casts conducted on 3 and 7 January 2010, near the time when the moorings were retrieved.

[11] Hourly averaged current, temperature, and wind data were low-pass filtered using a PL64 filter [Beardsley et al., 1985], with a half power period of $38 \mathrm{~h}$, to remove tidal and inertial fluctuations. The current vectors were rotated using a Principal Component Analysis (PCA) of the depthaveraged current variance projected into along-shelf $(u)$ and cross-shelf directions $(v)$ based on the major and minor axes, respectively [Emery and Thomson, 2001] (Figure 2b). A sign convention was used where the positive along-shelf direction $(x)$ is equatorward (along the coast to the north) and the positive cross-shelf direction $(y)$ is directed offshore. The ADCP measurements were not available very near the surface (typically $<10 \mathrm{~m}$ for M2 and M3 

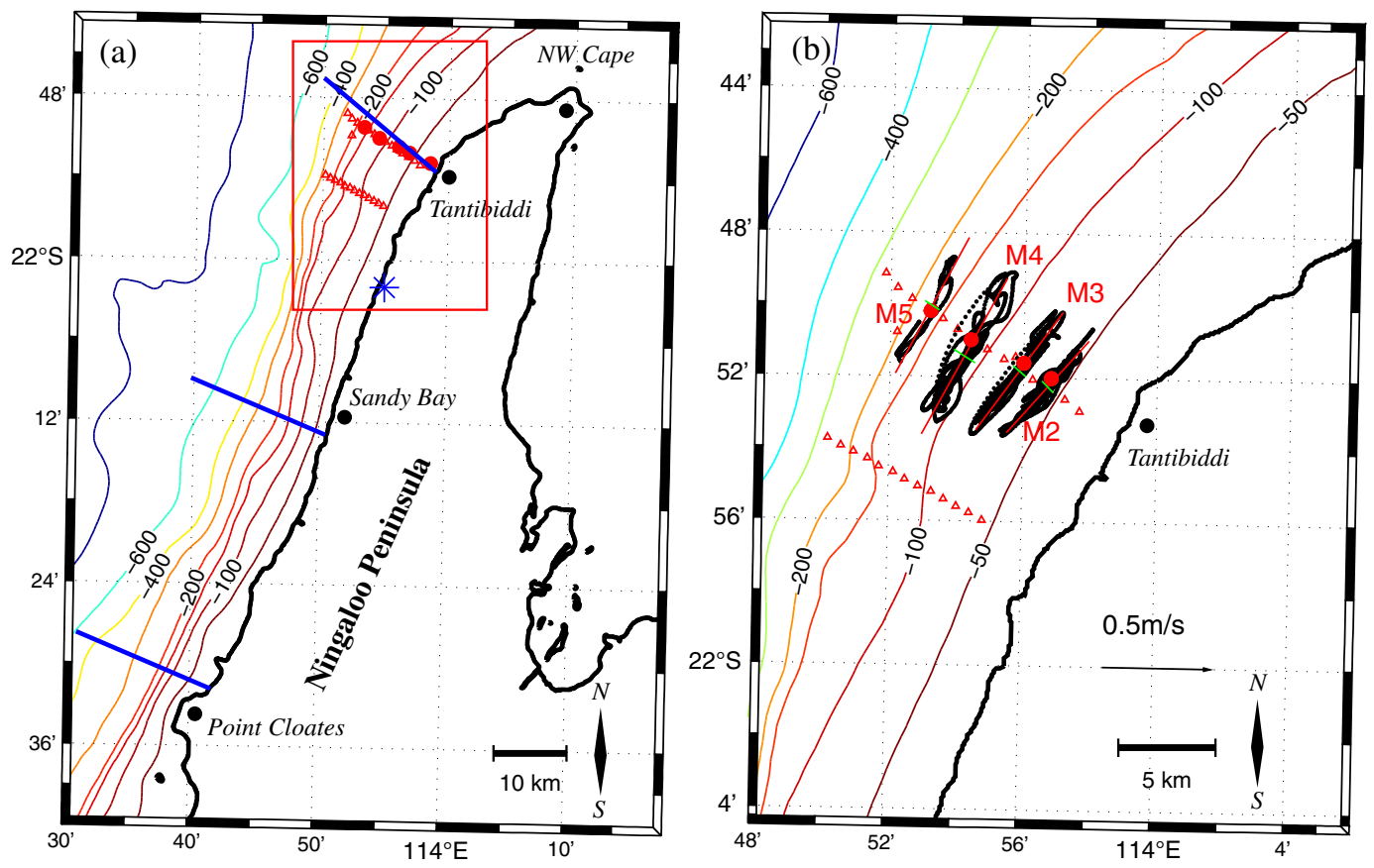

Figure 2. (a) The location of the moorings (red dots), CTD casts (red triangles), and three cross-shelf sections where the detailed model analysis were conducted superimposed (blue lines). The blue asterisk denotes the location of the weather station at Milyering. (b) A zoomed in region (red box) of Figure 1a, with scatter plots of subtidal depth-averaged currents superimposed (black cloud). The mooring sites are labeled M2 to M5 from onshore to offshore. The major axes from the PCA analysis of the current variance are included as red lines, while the minor axes are denoted by green lines. The along-shelf $(u)$ current directions (aligned with each major axis) were defined as positive (nautical convention) $45^{\circ}$ for $\mathrm{M} 2,38^{\circ}$ for M3, and approximately $30^{\circ}$ for M4 and M5.

Table 1. Mooring Locations and Instrument Descriptions

\begin{tabular}{|c|c|c|c|c|c|}
\hline \multirow[b]{2}{*}{ Mooring } & \multicolumn{2}{|c|}{ Location [Degrees] } & \multirow{2}{*}{$\begin{array}{c}\text { Site } \\
\text { Depth }[\mathrm{m}]\end{array}$} & \multirow[b]{2}{*}{ Currents (Bin Size $[\mathrm{m}]$ ) } & \multirow{2}{*}{$\begin{array}{c}\text { Temperature }(\text { Height Above } \\
\text { Bottom }[\mathrm{m}])^{\mathrm{a}}\end{array}$} \\
\hline & Longitude & Latitude & & & \\
\hline M2 & 113.947 & -21.8669 & 55 & $600 \mathrm{kHz}$ Nortek Aquadopp profiler (4) & $\mathrm{T}(28,38,43)$ \\
\hline M3 & 113.9332 & -21.8599 & 79 & $300 \mathrm{kHz}$ RDI Workhorse ADCP (2) & $\begin{array}{l}\text { T }(4,7,11,14,17,20,24,27,30,36,39,42, \\
45,51,54,57) ; \text { TP }(33,60)\end{array}$ \\
\hline M4 & 113.9068 & -21.8497 & 108 & 300 kHz RDI Workhorse ADCP (4) & $\mathrm{T}(83)$ \\
\hline M5 & 113.8867 & -21.8365 & 151 & 150 kHz RDI Workhorse ADCP (2) & $\begin{array}{l}\text { Т }(4,11,21,31,41,61,71,81.6,95,100,105, \\
110,116,122,128,134) ; \text { TP }(51,89,140)\end{array}$ \\
\hline
\end{tabular}

a“T" denotes SBE39s with just a temperature sensor, while those denoted "TP" also included a pressure sensor.

and $\sim 15 \mathrm{~m}$ for M4) due to side lobe interference. Consequently, for subsequent calculations of the cross-shelf surface depth-integrated volume transport (see section 2.4 for details), estimates of the velocities in this near-surface region were included by interpolating velocities from just below. The spatial characteristics of the current and temperature variability were investigated by using an Empirical Orthogonal Function (EOF) analysis [Emery and Thomson, 2001]. When reporting the results below, the EOF spatial modes were multiplied by the standard deviations of the associated modal amplitude time series (hence, these have the same units as the original data time series). Lagged correlations were also computed between variables with significances levels quantified based on the effective degrees of freedom $(\sim 37)$ estimated from the record length divided by the autocorrelation time scale [Emery and Thomson, 2001].

\subsection{Model Setup}

[12] The numerical simulations were conducted by using the Regional Ocean Modeling System (ROMS) [Haidvogel et al., 2008] (version 3.6), a free-surface, terrain-following (sigma coordinate), primitive equation ocean model (http:// www.myroms.org) that has been widely used in a diverse range of coastal applications [e.g., Cervantes and Allen, 2006; Haidvogel et al., 2008; Meuleners et al., 2007]. A number of studies have successfully applied ROMS to investigate the upwelling dynamics in other coastal regions, e.g., along the Northern California coast, and these literatures helped guide the configuration of this present modeling [Cervantes and Allen, 2006; Marchesiello et al., 2003]. Coastal processes such as upwelling can only be resolved with relatively high spatial resolution (i.e., much finer than 
the local baroclinic Rossby radius of deformation); however, they may also be strongly influenced by much largerscale and remotely generated mesoscale ocean dynamics $(>100 \mathrm{~km})$, as is the case for the Ningaloo coast. These disparate temporal and spatial scales required the development of a double nested ROMS model. This consisted of a relatively coarse-resolution (2-3 km grid spacing) model of the broader WA coastal region (hereinafter referred to as the "WAC" model) and a fine-resolution (500 $\mathrm{m}$ grid spacing) model surrounding Ningaloo Reef itself (hereinafter referred to as the "NF" model) (Figure 3). The coarse WAC model included more than $1000 \mathrm{~km}$ of coastline (extending from south of Shark Bay to north of Port Hedland), whereas the fine NF model enclosed the $\sim 400 \mathrm{~km}$ of coast surrounding the Ningaloo Peninsula (Figure 3). Hindcast model simulations were achieved by both initializing the WAC model and forcing its open boundaries with daily two-dimensional surface elevation fields, as well as three-dimensional velocity, temperature, and salinity fields from the Hybrid Coordinate Ocean Model reanalysis system (HYCOM; www.hycom.org), a global data-assimilating ocean model with $1 / 12^{\circ}$ resolution [Chassignet et al., 2007]. A comparison of HYCOM and field CTD data showed that HYCOM tended to accurately predict the vertical stratification during the summer study period (section 3.1). The inner nested NF model was then initialized and forced at its open boundaries by output from the WAC model. There is a relatively small tidal range $(<1 \mathrm{~m})$ in the Ningaloo region, and initial testing of the NF model with tides included had minimal influence on the subtidal shelf circulation and stratification; therefore, tidal forcing was not included in subsequent modeling.

[13] We used gridded bathymetric data with a horizontal resolution of $250 \mathrm{~m}$, available from Geoscience Australia (2009 release). To improve the stability and accuracy of the model in areas of localized steep topography, three modifications were applied to the original interpolated bathymetry: (1) a minimum and maximum depth in the model domain was specified (in the coarse model 10 and $5500 \mathrm{~m}$, respectively; in the fine model 10 and $2000 \mathrm{~m}$, respectively),

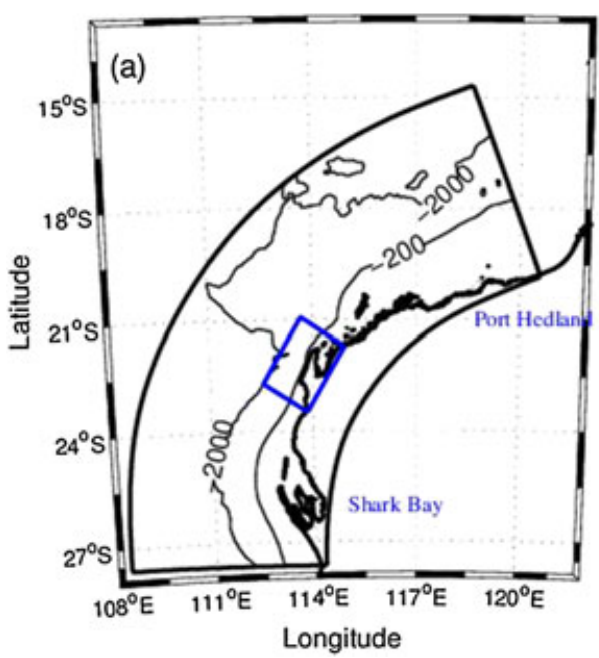

(2) the bathymetry was smoothed to limit the "Beckman and Haidvogel number" (topographic stiffness ratio) $r x_{0}<0.2$ [Beckmann and Haidvogel, 1993] and the "Haney number" (hydrostatic instability number) $r x_{1}<6$ [Haney, 1991; Martinho and Batteen, 2006], and (3) the bathymetry was gradually transitioned between model domains by interpolating values from the outer model grid onto the inner model grid adjacent to the open boundaries to allow stable nesting. For model nesting, the grid ratio between two models should nominally be no more than 5:1 [Spall and Holland, 1991]. In our models, this downscaling ratio was around 4:1, i.e., HYCOM to WAC ( $\sim 9 \mathrm{~km}$ to $\sim 2-3 \mathrm{~km})$ and WAC to NF $(\sim 2-3 \mathrm{~km}$ to $500 \mathrm{~m})$. The WAC and NF models contained 40 vertical sigma levels, with a critical depth $h_{c}=10 \mathrm{~m}$, a surface stretching factor of $\theta_{s}=3$, and a bottom stretching factor of $\theta_{b}=0.4$, maintaining a higher vertical resolution on the surface layer. For the present application, we apply the continuous double stretching function with separate surface and bottom refinement described in Shchepetkin and McWilliams [2009](i.e., Vstretching = 4 in ROMS). At the $100 \mathrm{~m}$ isobaths, this resulted in an average resolution of $1.5 \mathrm{~m}$ in the surface half of the water column and $5 \mathrm{~m}$ resolution in the bottom.

[14] Sub-grid scale horizontal mixing (eddy viscosity) was parameterized as a function of the local grid resolution using a Smagorinsky formulation [Smagorinsky, 1963]. For vertical mixing, ROMS includes a number of two-equation turbulent closure schemes [Warner et al., 2005]; these include, for example, the Mellor-Yamada Level 2.5 (MY2.5), $k-\varepsilon, k-\omega$, and the generic length-scale (gen) scheme of Umlauf and Burchard [2003]. The influence of these turbulent closure schemes on the results (momentum and scalars) was initially investigated by conducting a series of sensitivity tests (Appendix A1).

[15] Wind stresses were prescribed on the surface using a quadratic drag formulation based on the wind speed and surface drag coefficients from Large and Pond [1981]. Bottom stresses were calculated internally by assuming a bottom boundary layer with a logarithmic velocity profile

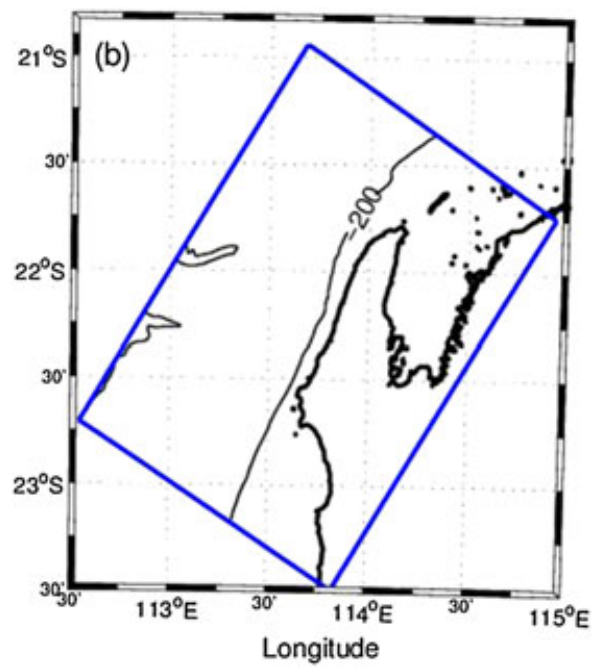

Figure 3. (a) The coarse (WAC) model domain outlined by the solid black line, with the fine (NF) model domain outlined by the blue box. The $200 \mathrm{~m}$ and $2000 \mathrm{~m}$ depth contours are indicated by the back line, while the coastline is denoted by the bold black line. (b) Zoomed in view of the nested NF model domain outlined with the blue box in Figure $3 a$. 
within the bottom grid cell and a uniform hydraulic roughness length $z_{o}$ taken as $0.02 \mathrm{~m}$ (the default in ROMS), which is equivalent to a bottom quadratic coefficient $C_{d} \sim 0.005$ at a reference height of $10 \mathrm{~m}$. The pressure-gradient term was solved with a spline density Jacobian [Shchepetkin and McWilliams, 2003] to minimize errors associated with computing horizontal pressure gradients in the terrain-following coordinates. A third-order, upwind-biased scheme computed the horizontal momentum and tracer advection, and a fourthorder, centered scheme was used for the vertical advection. Horizontal diffusion of tracers (e.g., temperature and salinity) was defined along the geopotential surfaces, which can greatly reduce the error associated with using sigma (terrainfollowing) coordinate systems [Beckmann and Haidvogel, 1993]. To maintain a numerically stable adjustment to the time evolving solution, a nudging (sponge) zone adjacent to the open boundaries was incorporated with locally enhanced viscosity/diffusion. The lateral boundary conditions of the inner NF model were provided from the outer WAC model using offline one-way nesting. Based on initial model testing, we found that the following boundary condition options within ROMS were most suitable for these hindcast simulations: Chapman [1985] (FSCHAPMAN) and Flather [1976] (M2FLATHER) gravity-wave radiation conditions for surface elevations and barotropic velocities, respectively; Orlanski [1976] type radiation conditions for baroclinic velocities (M3RADIATION) as well as tracers such as temperature and salinity (TRADIATION); and nudging for both baroclinic velocities (M3NUDGING) and tracers (TNUDGING) (e.g., refer to Marchesiello et al. [2001] for details).

[16] The hindcast simulations used hourly wind vector fields $\left(0.3^{\circ}\right.$ resolution) available from the UCAR Climate Forecast System Reanalysis [Saha et al., 2010]. A comparison of the UCAR winds with the observed winds at the Milyering weather station showed high correlation $R=0.92(p<0.01)$, albeit the UCAR winds were $\sim 20 \%$ larger on average (not shown), possibly due to coastal topographic sheltering at the shore-based weather station (see discussion below). Additional atmospheric properties were obtained from the NCEP/NCAR Reanalysis (http:// www.esrl.noaa.gov/psd/data/reanalysis/reanalysis.shtml), available 6 hourly with coarser spatial resolution of $2.5^{\circ}$, where the surface heat fluxes over the model domain were computed using a bulk flux parameterization [Fairall et al., 1996]; hence, solar short wave radiation, long wave radiation, and latent and sensible heat fluxes were all included.

[17] Different measures of model performance were quantitatively compared to the field observations by computing the correlation coefficient $(R)$, a mean time-averaged difference (Bias), the root-mean-square error (RMSE), and model skill defined as Willmott [1981]

$$
\text { skill }=1-\frac{\sum\left|X_{\text {model }}-X_{\text {obs }}\right|^{2}}{\sum\left(\left|X_{\text {model }}-\overline{X_{\mathrm{obs}}}\right|+\left|X_{\mathrm{obs}}-\overline{X_{\mathrm{obs}}}\right|\right)^{2}}
$$

where $X$ is the variable being compared with its timeaveraged value $\bar{X}$. Perfect agreement between the model predictions and field observations yield a skill $=1$, whereas complete disagreement yields a skill $=0$.

\subsection{Momentum and Transport Analysis}

[18] We used outputs from the numerical model to quantify the importance of the various mechanisms responsible for driving the current variability on the shelf. The depthaveraged momentum equations in a sigma coordinate system are given as [e.g.,Blumberg and Mellor, 1987; Gan and Allen, 2002]

$$
\begin{aligned}
& \frac{\partial U}{\partial t}=\overbrace{-\left(\frac{\partial(U U)}{\partial x}+\frac{\partial(V U)}{\partial y}-\frac{G_{x}}{D}\right)}^{2}+\overbrace{\left(-\frac{1}{D} \int_{-1}^{0} \frac{H_{z}}{\rho_{0}} \frac{\partial P}{\partial x} d \sigma\right.}^{3} \\
& +\left(\frac{\tau_{x s}}{D \rho_{0}}-\left(\frac{\tau_{x b}}{D \rho_{0}}\right)\right)_{7}+f V \\
& +\overbrace{\frac{1}{\rho_{0}}\left(\frac{\partial}{\partial x}\left(K_{H} \frac{\partial U}{\partial x}\right)+\frac{\partial}{\partial y}\left(K_{H} \frac{\partial U}{\partial y}\right)\right)} \\
& \frac{\partial V}{\partial t}=\overbrace{-\left(\frac{\partial(V U)}{\partial x}+\frac{\partial(V V)}{\partial y}-\frac{G_{y}}{D}\right)}^{2}+\overbrace{\left(-\frac{1}{D} \int_{-1}^{0} \frac{H_{z}}{\rho_{0}} \frac{\partial P}{\partial y} d \sigma\right)}^{3} \\
& +\left(\frac{\tau_{y s}}{D \rho_{0}}-\left(\frac{\tau_{y b}}{D \rho_{0}}\right)\right)_{7}-f U \\
& +\overbrace{\frac{1}{\rho_{0}}\left(\frac{\partial}{\partial x}\left(K_{H} \frac{\partial V}{\partial x}\right)+\frac{\partial}{\partial y}\left(K_{H} \frac{\partial V}{\partial y}\right)\right)}
\end{aligned}
$$

Here $U$ and $V$ are the depth-averaged along-shelf $(x)$ and cross-shelf $(y)$ velocities, respectively, $G_{x}$ and $G_{y}$ represent the vertical averages of the cross-products of the velocity departures from the vertically integrated velocity (referred to as dispersion terms) [Blumberg and Mellor, 1987; Whitney and Allen, 2009], $D$ is the water depth, $H_{z}$ is a vertical stretching factor, $f$ is the Coriolis frequency, $P$ is pressure, $\rho_{0}$ is the reference density, and $K_{H}$ denotes the horizontal eddy viscosity. The terms in equation (2) represent the (1) local acceleration, (2) nonlinear horizontal advection, (3) pressure gradient, (4) surface wind stress, (5) bottom stress, (6) Coriolis force, and (7) horizontal viscosity term. The positive alongshelf direction $(x)$ was defined as along the major axis of the depth-averaged current variance toward the northeast, based on the PCA analysis (section 2.2). However, when analyzing the spatial distribution of momentum terms along the coast with the model, a fixed coordinate system (along-shelf axis at $31^{\circ}$, nautical convention clockwise from north) was assumed based on the mean coastline orientation along the relatively straight Ningaloo Peninsula.

[19] As the Coriolis and pressure gradient terms usually work together to form a geostrophic equilibrium, in our analysis we combined terms (3) and (6) as an "ageostrophic pressure gradient" to subtract these geostrophic components. This definition makes it easier to examine the role of the wind forces interacting with the pressure gradient in the along-shelf momentum balance analysis [Cervantes and Allen, 2006]. The horizontal viscosity term (7) was significantly smaller than the other terms by typically two orders of magnitude, thus not considered in the momentum analysis below. 
[20] To examine the influence of wind on coastal upwelling, the cross-shelf transport $q_{\text {cross }}$ (units $\mathrm{m}^{2} \mathrm{~s}^{-1}$ ) within the surface Ekman layer was computed as [Dever, 1997; Lentz, 2001]

$$
q_{\mathrm{cross}}=\int_{-D_{E}}^{0} \widetilde{v} d z
$$

Here $D_{E}$ denotes the surface Ekman layer depth, estimated as a function of the local wind stress and stratification following Lentz [1992], and $\widetilde{v}=v-v_{\text {ref }}$ denotes the crossshelf velocity with an interior cross-shelf reference velocity removed from the profile to remove any transport contribution from a geostrophic interior flow. For $v_{\text {ref, }}$, we considered both using the depth-averaged velocity [e.g., Lentz, 2001] as well as assuming an interior velocity taken as the value measured at the base of the estimated Ekman layer $D_{E}$ [e.g., Lentz, 1992]. In addition, the vertical transport $q_{\text {vert }}$ (units $\mathrm{m}^{2} \mathrm{~s}^{-1}$ ) near the bottom of the Ekman layer was evaluated as

$$
q_{\mathrm{vert}}=\int_{0}^{L_{U}} w d y
$$

where $L_{U}$ denotes the distance of a particular sampling site from the coast and $w$ denotes the vertical velocity at the base of the Ekman layer.

[21] At different distances offshore, both $q_{\text {cross }}$ and $q_{\text {vert }}$ were compared with the theoretical Ekman transport $q_{E}$ predicted from the along-shelf wind stress $\tau_{x s}$ as

$$
q_{E}=-\frac{\tau_{x s}}{\rho_{0} f}
$$

For the model, both the cross-shelf transport $q_{\text {cross }}$ and vertical transport $q_{\text {vert }}$ were directly computed. However, field measurements of vertical velocity $w$ were too weak (i.e., comparable to the uncertainty in the ADCP measurements) to provide a robust measure of $q_{\text {vert }}$; therefore, only the cross-shelf transport $q_{\text {cross }}$ was derived from the field measurements.

\subsection{Heat Budget Analysis}

[22] Both the field and model results were used to investigate the relative magnitude of various components of the heat budget in controlling temperature variability along the Ningaloo coast. This analysis was similar to that described in Gan and Allen [2002]. The general conservative expression for the potential temperature budget in a control volume $\forall$ is given by

$\rho c_{p} \frac{d}{d t} \iiint T \forall \forall=-\rho c_{p}\left(\iiint \frac{\partial(u T)}{\partial x} d \forall+\iiint \frac{\partial(v T)}{\partial y} d \forall+\iiint \frac{\partial(w T)}{\partial z} d \forall\right)+\dot{Q}$

[23] Here $T$ is the potential temperature, $\dot{Q}$ is the net total surface heat flux (with units $W$ ), and $c_{p}$ is the specific heat capacity of seawater. Note that equation (7) neglects the horizontal diffusion terms, which are much smaller than the advection terms (subsequently confirmed in the numerical modeling). As noted by Gan and Allen [2002], the general form of each advection term in equation (7) contains large transport terms (e.g., terms such as $T \partial u / \partial x$ in the alongshelf direction) that do not contribute to temperature variation in the control volume. These terms cancel when added together but depend on the absolute temperature scale when considered separately.

\subsubsection{Model Output Analysis}

[24] When examining the heat budget, we treated the field data and model outputs differently due to inherent spatial resolution limitations of the field data. Using the model output, we first define the average temperature $T_{\text {avg }}$ within the control volume as

$$
T_{\text {avg }} \equiv \frac{1}{\forall} \iiint T d \forall
$$

and define a net combined cross-shelf and vertical transport term $Q_{\text {net }}$ (equivalent to the net along-shelf transport, with units $\left.\mathrm{m}^{3} \mathrm{~s}^{-1}\right)$ as

$$
Q_{\text {net }}=\iiint\left(\frac{\partial v}{\partial y}+\frac{\partial w}{\partial z}\right) d \forall=-\iiint \frac{\partial u}{\partial x} d \forall
$$

Equation (7) then becomes

$$
\begin{aligned}
\overbrace{\frac{1}{\forall} \frac{d}{d t} \iiint_{T} \forall}^{1}= & -\overbrace{\frac{1}{\forall}\left(\oiint u T d \vec{A}+T_{\mathrm{avg}} Q_{\mathrm{net}}\right)}^{2} \\
& +\overbrace{-\frac{1}{\forall}\left(\oiint(v T+w T) d \vec{A}-T_{\mathrm{avg}} Q_{\mathrm{net}}\right)}^{3}+\overbrace{\dot{Q} /\left(\rho c_{p} \forall\right)}^{4}
\end{aligned}
$$

or equivalently

$$
\frac{\partial T_{\mathrm{avg}}}{\partial t}=\overbrace{T A D V}^{2} x+\overbrace{T A D V_{y z}}^{3}+\overbrace{\dot{Q} /\left(\rho c_{p} \forall\right)}^{4}
$$

where the volume integrals of the advection terms have been converted to surface integrals using Gauss' theorem. In both equations (10) and (11), term 1 describes changes in heat content inside the control volume, term 2 represents the along-shelf advection of heat through the control volume faces, term 3 describes the combined cross-shelf and vertical advection of heat, and term 4 is a source term affected by surface heat fluxes. We note that the cross-shelf and vertical transport components are combined in equations (10) and (11), since these terms potentially act together; e.g., during upwelling, an upward flow toward the coast is generated. Each term in equation (11) was estimated daily based on the available model outputs; as such, any heat fluxes associated with higher (greater than subtidal) frequency variability are not considered here.

[25] The individual terms in equation (11) were calculated within the control volume specified in Figure 4. The crossshelf dimension $(\sim 15 \mathrm{~km})$ was chosen as 1.5 times the local internal Rossby radius of deformation $(R=N H / f)$, where the buoyancy frequency $N$ and associated scale height $H$ were representative of the thermocline region. We note that changes to the control volume by subtidal water level variations were minimal (altering the total volume by $<0.01 \%$ of the total volume during the study) and hence were neglected.

\subsubsection{Field Analysis}

[26] With this cross-shelf mooring array, we could only estimate the direct contribution from the cross-shelf heat flux term $\dot{q}_{\text {cross }}\left[\mathrm{W} \mathrm{m}{ }^{-1}\right.$ ], i.e. [Dever and Lentz, 1994; Richman and Badan-Dangon, 1983] 


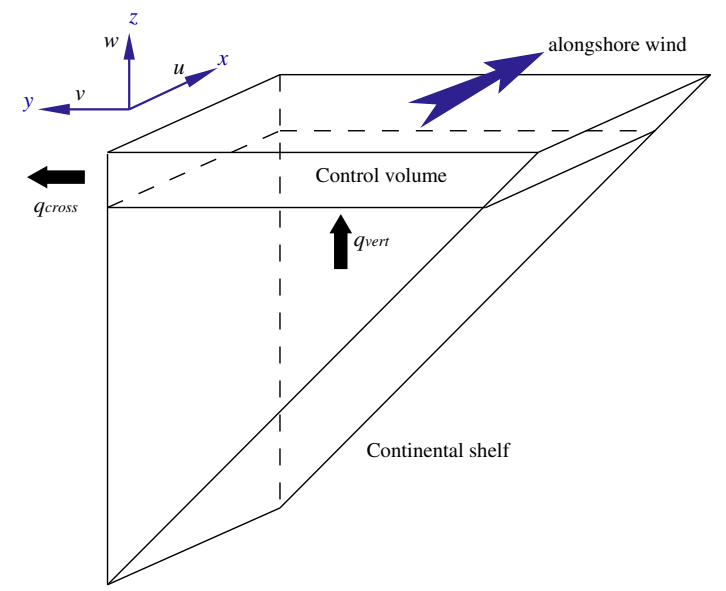

Figure 4. Schematic diagram of the control volume used to conduct the heat budget analysis. $q_{\text {vert }}$ is the vertical volume flux through the bottom face of the control volume, while $q_{\text {cross }}$ is the corresponding cross-shelf transport. The control volume was defined as $15 \mathrm{~km}$ from the coast within a $50 \mathrm{~m}$ surface layer, with a unit $(1 \mathrm{~m})$ along-shelf length. Here $x, y$, and $z$ axes denote the along-shelf, cross-shelf, and vertical directions, respectively.
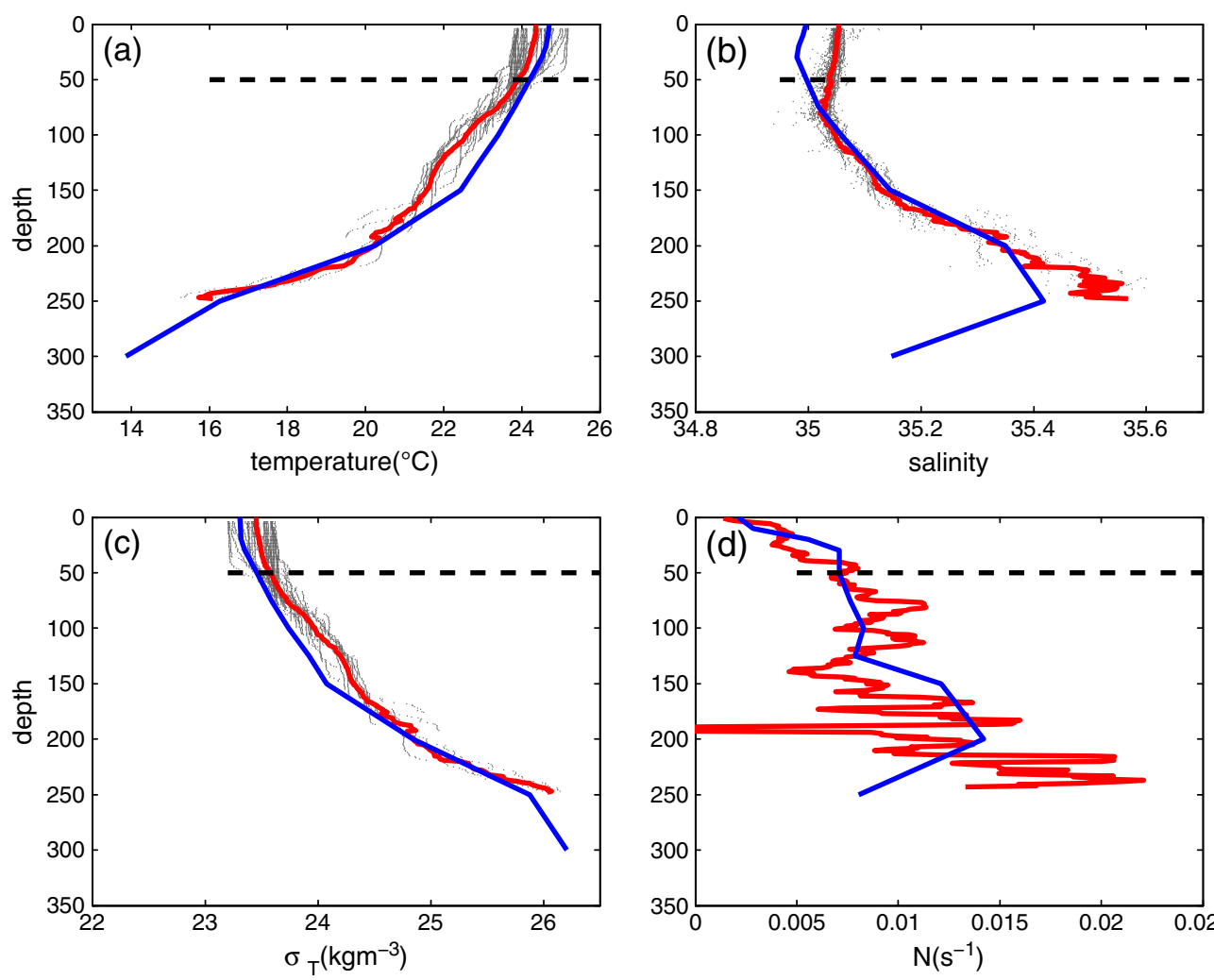

Figure 5. (a) The vertical distribution of temperature $\left[{ }^{\circ} \mathrm{C}\right]$, (b) salinity, (c) $\sigma_{T}$ (defined as potential density minus $1000 \mathrm{~kg} \mathrm{~m}^{-3}$ ), and (d) buoyancy frequency $N\left[\mathrm{~s}^{-1}\right]$ offshore of Ningaloo in January 2010. The gray dotted lines denote the individual CTD casts conducted, and the thick red lines denote the mean profile. The thick blue lines represent the mean profiles from HYCOM at Ningaloo during the same period as the field observations. The surface mixed layer is highlighted by the horizontal dashed line. Note: the locations of these CTD casts were described in Figure 2 by red triangles. 
density gradient (i.e., salinity contributions were minimal). Accordingly, the buoyancy frequency was typically $\sim 0.005-0.010 \mathrm{~s}^{-1}$ within the surface $100 \mathrm{~m}$. The surface mixed layer depth in summer was approximately $50 \mathrm{~m}$ deep, highlighted by the dashed line in Figure 5. A deep pycnocline was present below $200 \mathrm{~m}$ depth, corresponding to a deep salinity maximum due to the presence of South Indian Central Water (peak salinity at $\sim 300 \mathrm{~m}$ depth) below the LC that is a persistent feature off the West Australian coast [Woo and Pattiaratchi, 2008].

\subsection{Wind and Current Variability}

[28] Time series of the wind vectors recorded at the weather station are plotted in Figure 6a, showing five main upwelling favorable wind events (towards the northeast) interspersed by short relaxation intervals when the wind speeds dropped to nearly zero. During these 2 months, the wind varied with time scales of roughly $1-2$ weeks, with a vector-averaged along-shelf velocity of $6 \mathrm{~m} \mathrm{~s}^{-1}$, equivalent to a mean wind stress of $\sim 0.05 \mathrm{~N} \mathrm{~m}^{-2}$ (Table 2). A PCA analysis of the wind velocity variance gave a major axis of $35^{\circ}$ (nautical convention, clockwise from north), thus closely aligned with the orientation of the coastline $\left(\sim 30^{\circ}\right)$.

[29] The major axes of the depth-averaged subtidal current variance varied over the cross-shelf mooring transect, from roughly $45^{\circ}$ at $\mathrm{M} 2$, to $38^{\circ}$ at $\mathrm{M} 3$, to roughly $30^{\circ}$ at $\mathrm{M} 4$; the flows are thus roughly parallel to the local isobaths (Figure $2 b$ ). There were two periods of strong $\left(>0.5 \mathrm{~m} \mathrm{~s}^{-1}\right)$ northward flow (Figures 6b-6d): the first occurred from 14 to 21 November and the second from 21 to 24 December. In both cases, these were followed by strong reversals (southward flow) occurring within 2 days after the wind relaxed. The strength of the along-shelf currents tended to increase offshore, with the currents mostly flowing unidirectionally through the water column at all sites. The time- and depthaveraged along-shelf current velocity was weakly southward (negative value), ranging from $-0.041 \mathrm{~m} \mathrm{~s}^{-1}$ at $\mathrm{M} 2$ to $-0.089 \mathrm{~m} \mathrm{~s}^{-1}$ at M4 (Table 2).

[30] The cross-shelf current profiles, however, show substantial vertical variability through the water column (Figure 7). During strong northward wind events, offshoredirected (positive) flows generally occurred near the surface with onshore (negative) flows deeper in the water column,
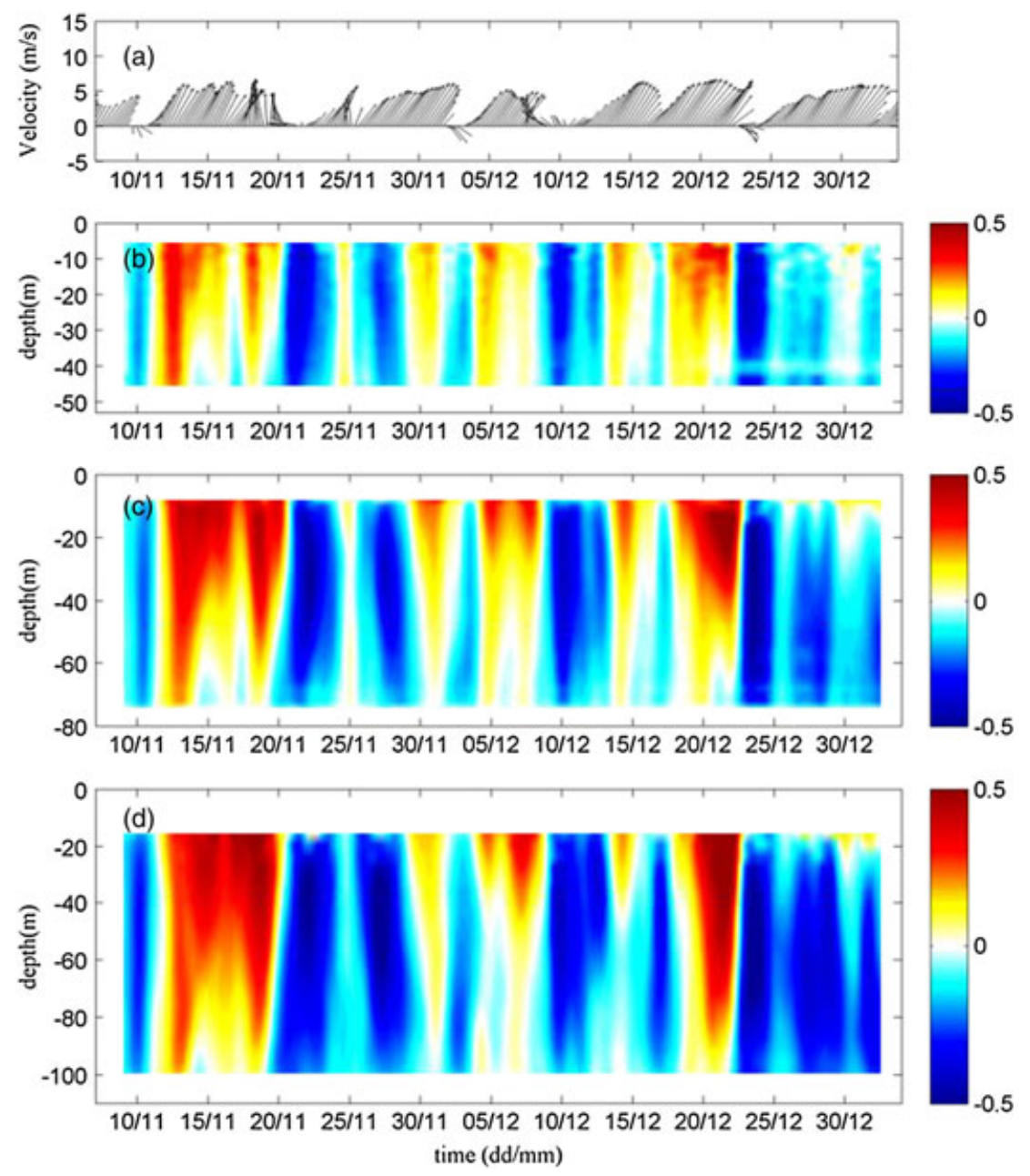

Figure 6. (a) Time series (November 2009 to January 2010) of low-pass filtered wind vectors [ $\mathrm{m} \mathrm{s}^{-1}$ ] observed at the weather station (with true north upwards). (b, c, d) Time series of the along-shelf subtidal velocities at moorings (b) M2, (c) M3, and (d) M4. The positive along-shelf direction is toward the northeast, oriented along the principle directions shown in Figure 2. The color bars denote the along-shelf current speed in $\mathrm{m} \mathrm{s}^{-1}$. The vertical scale of Figures $6 \mathrm{~b}-6 \mathrm{~d}$ covers the full water column depth. 
Table 2. Summary Statistics of Field Observations at the Four Mooring Sites ${ }^{\mathrm{a}}$

\begin{tabular}{|c|c|c|c|c|c|c|c|c|c|c|c|c|}
\hline \multirow[b]{2}{*}{ Variable } & \multicolumn{4}{|c|}{ Mean } & \multicolumn{4}{|c|}{ STD } & \multicolumn{4}{|c|}{$R$} \\
\hline & M2 & M3 & M4 & M5 & M2 & M3 & M4 & M5 & M2 & M3 & M4 & M5 \\
\hline Wind stress $\left[\mathrm{N} \mathrm{m}^{-2}\right]$ & 0.053 & 0.053 & 0.053 & 0.053 & 0.027 & 0.027 & 0.027 & 0.027 & - & - & - & - \\
\hline$U\left[\mathrm{~m}^{-1}\right]$ & -0.041 & -0.044 & -0.089 & - & 0.15 & 0.179 & 0.209 & - & $0.73(10 \mathrm{~h})$ & $0.71(21 \mathrm{~h})$ & $0.65(21 \mathrm{~h})$ & - \\
\hline$V\left[\mathrm{~m}^{-1}\right]$ & -0.016 & -0.002 & -0.012 & - & 0.02 & 0.02 & 0.029 & - & $0.31(8 \mathrm{~h})$ & $0.63(13 \mathrm{~h})$ & $0.43(20 \mathrm{~h})$ & - \\
\hline$\frac{\partial T}{\partial t}\left[{ }^{\circ} \mathrm{C} \mathrm{d}^{-1}\right]$ & - & -0.013 & - & -0.018 & - & 0.438 & - & 0.31 & - & $-0.89(12 \mathrm{~h})$ & - & $-0.75(12 h)$ \\
\hline$\dot{q}_{\text {cross }}\left[10^{6} \mathrm{~W} \mathrm{~m}^{-1}\right]$ & - & -2.3 & - & - & - & 3.8 & - & - & - & $-0.6(18 \mathrm{~h})$ & - & - \\
\hline
\end{tabular}

${ }^{a}$ Mean and STD denote the mean and standard deviation, respectively, over the entire experiment. Here $U$ and $V$ refer to the depth-averaged along- and cross-shelf velocities, respectively; $R$ denotes the lagged correlation coefficient (time lag shown in the parentheses) between the along-shelf wind stress and the EOF amplitude of the first mode of $u, v$, and $\partial T / \partial t$, as well as with the cross-shelf heat flux $\dot{q}_{\text {cross. }}$. All correlation coefficients were significant $(p<0.05)$.
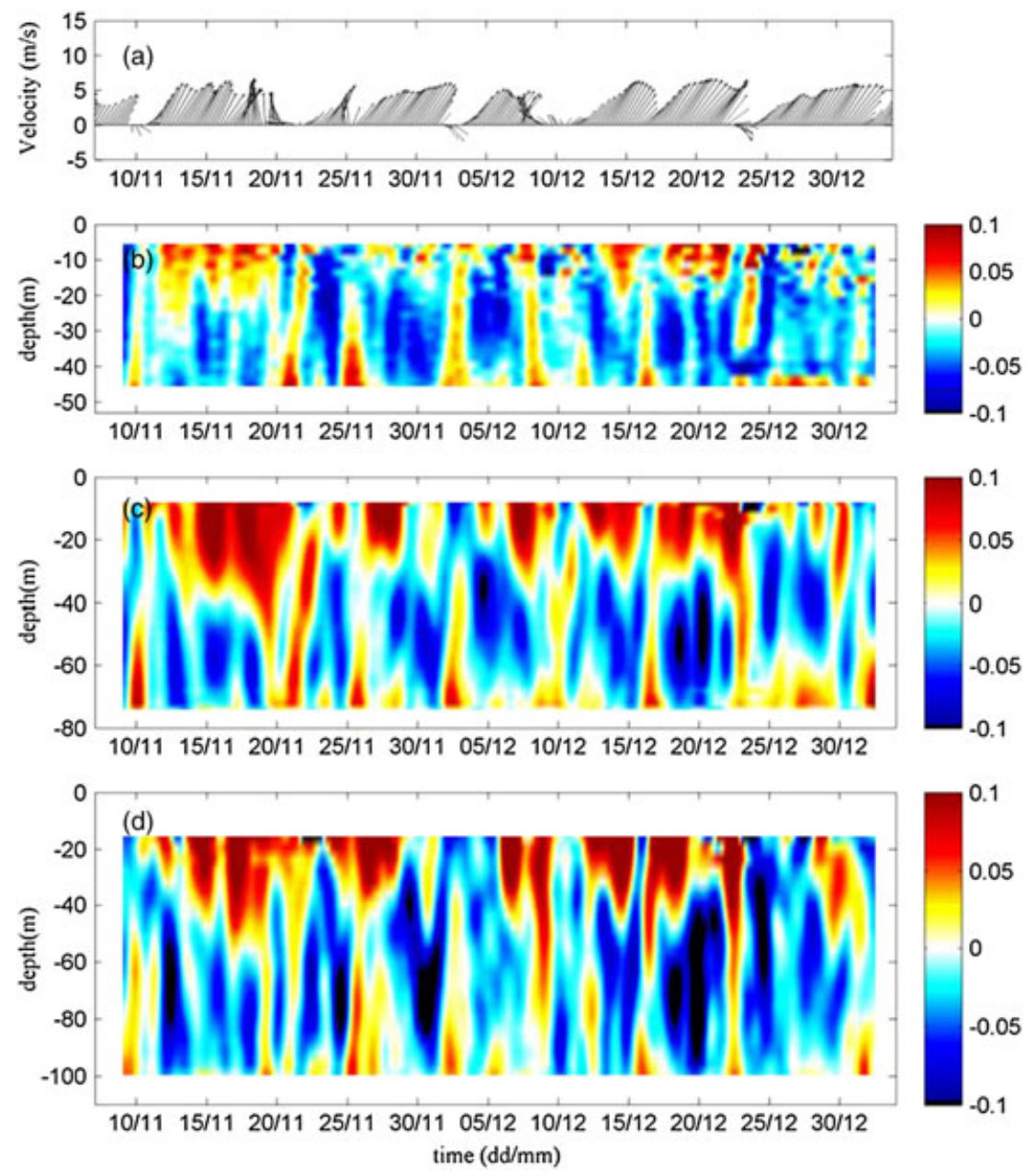

Figure 7. (a) Time series (November 2009 to January 2010) of low-pass filtered wind vectors [ $\mathrm{m} \mathrm{s}^{-1}$ ] observed at the weather station (with true north upwards). (b, c, d) Time series of the cross-shelf subtidal velocities at (b) M2, (c) M3, and (d) M4, respectively. The positive cross-shelf direction is directed offshore. The color bars denote the cross-shelf current speed $\left[\mathrm{m} \mathrm{s}^{-1}\right]$. The vertical scale of Figures $7 \mathrm{~b}-7 \mathrm{~d}$ covers the full water column depth.

suggestive of wind-driven coastal upwelling. This crossshelf current structure was also observed during periods when the along-shelf flow was southward (Figures $7 \mathrm{~b}-7 \mathrm{~d}$ ), but there was opposing northward (upwelling-favorable) wind stresses (e.g., during the period 23 November to 3 December). The cross-shelf current profiles show a maximum onshore (negative) flow located between the middle of the water column and the bottom, i.e., centered at $\sim 50-60 \mathrm{~m}$ for M3 (Figure $7 \mathrm{c}$ ) and $\sim 70 \mathrm{~m}$ for M4 (Figure $7 \mathrm{~d}$ ).
[31] Properties of the along-shelf and cross-shelf velocity profiles are summarized in Figure 8. The mean (timeaveraged over the experiment) along-shelf velocity near the surface was near zero or even weakly northward, while bottom waters flowed southward with increasing strength offshore (Figure 8a). The along-shelf current variability (expressed in terms of the standard deviation) and the structure of the first EOF mode displayed similar profile shapes with magnitudes increasing offshore (Figures $8 \mathrm{~b}$ and $8 \mathrm{c}$ ). 

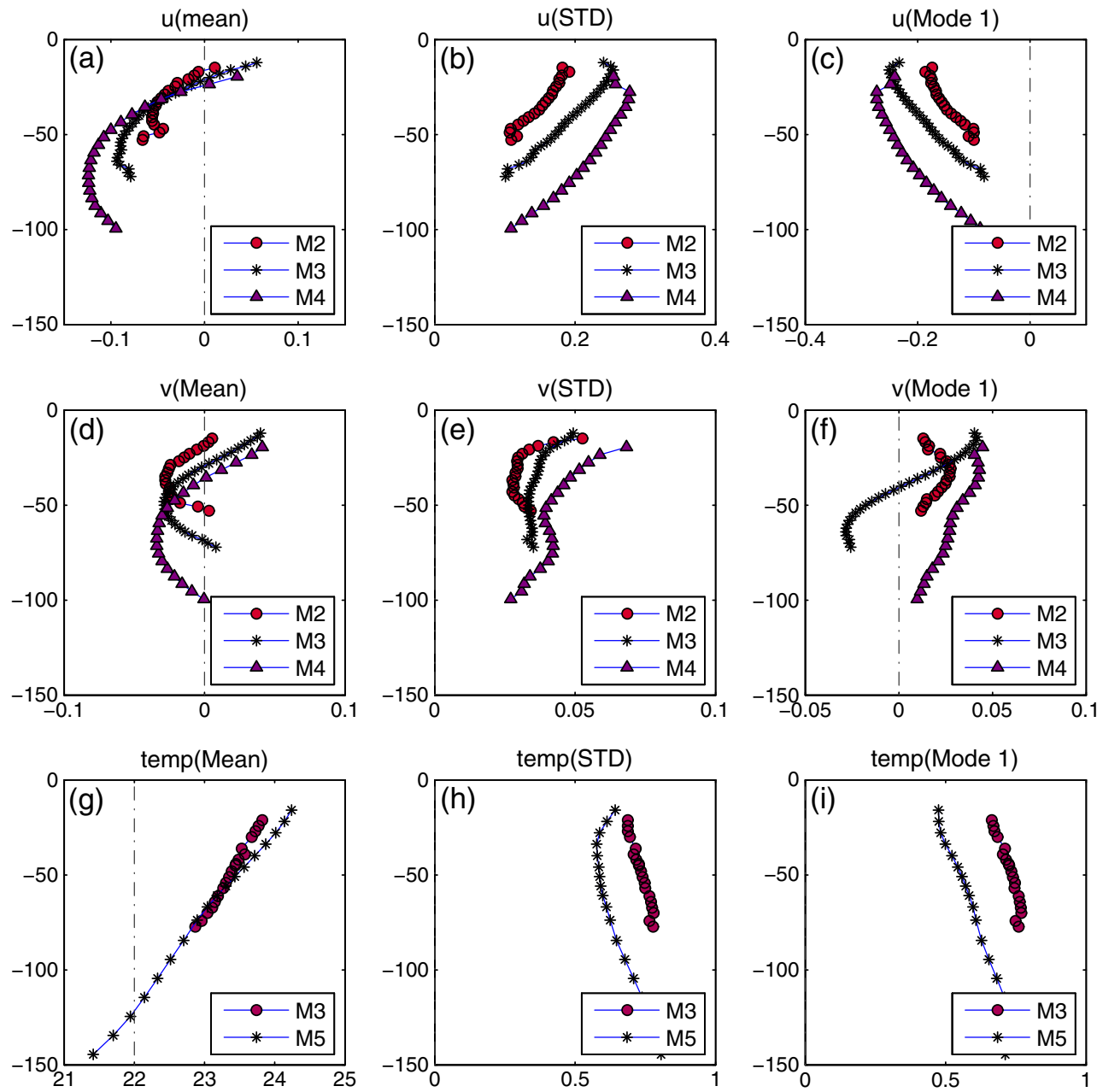

Figure 8. Statistical properties of the current and temperature profiles at the moorings. The mean (experiment-averaged) profile of the along-shelf velocity (in $\mathrm{m} \mathrm{s}^{-1}$ ), the cross-shelf velocity (in $\mathrm{m} \mathrm{s}^{-1}$ ), and temperature (in ${ }^{\circ} \mathrm{C}$ ) are shown in the first column ( $\mathrm{a}, \mathrm{d}, \mathrm{g}$ ), respectively; profiles of the standard deviation within the study period are shown in the second column $(b, e, h)$; the vertical structure of the first EOF mode is shown in the third column (c, f, i). Note that the EOF modes were multiplied by the square root of the variance in the time-varying EOF amplitude such that the units are the same as the original time series (i.e., units of $\mathrm{m} \mathrm{s}^{-1}$ for velocity; units of ${ }^{\circ} \mathrm{C}$ for temperature). Notably velocities at M5 were not available for the duration of the experiment due to instrument failure and hence are not included.

The first EOF mode of the along-shelf velocity explained $87 \%$ of the total variance, with only $5 \%$ explained by the second mode.

[32] For the cross-shelf velocities, the mean profiles displayed a pattern of offshore (positive) flow near the surface and onshore (negative) flow peaking above the bottom between 50 and $80 \mathrm{~m}$ depth, depending on the site (Figure 8d). The maximum standard deviation of cross-shelf flow occurred near the surface and gradually decreased with depth for all moorings (Figure 8e). The EOF analysis of the cross-shelf velocities revealed two primary modes that accounted for between 50-60\% (Mode 1) and 15-20\% (Mode 2) of the variance at all sites (only Mode 1 is shown in Figure 8f). We first note that the magnitude of the dimensional EOF values (Figure $8 \mathrm{f}$ ) is typically $<0.05 \mathrm{~m} \mathrm{~s}^{-1}$, indicating that this profile variability is superimposed on comparable or even larger mean cross-shelf currents. The first mode of M3 in particular showed a pattern of offshore (positive) flow near the surface and onshore (negative) flow (note that this pattern may reverse depending on the sign of the time-varying EOF amplitude), while no such pattern was observed at M2 and M4. In other words, at all sites there were mean (experiment-averaged) cross-shelf velocity profiles suggestive of upwelling (Figure 8d) that were modulated by the variability in Figure $8 \mathrm{f}$.

[33] Time series of the first EOF modal amplitude of the along-shelf velocities were used to quantify the relationship between the along-shelf currents and the along-shelf component of the wind stresses (Figure 9a). There was a strong correlation of $R=0.65-0.73$ when the along-shelf currents lagged the winds by $10-21 \mathrm{~h}$, emphasizing the importance of local wind forcing to the along-shelf current variability on the shelf during the study period (Table 2). Correlations with the cross-shelf velocities (Figure 9b) were lower, especially at the inshore mooring (M2), ranging from $0.31(8 \mathrm{~h})$ at M2 to 0.64 (13 h) at M3 (Table 2). 

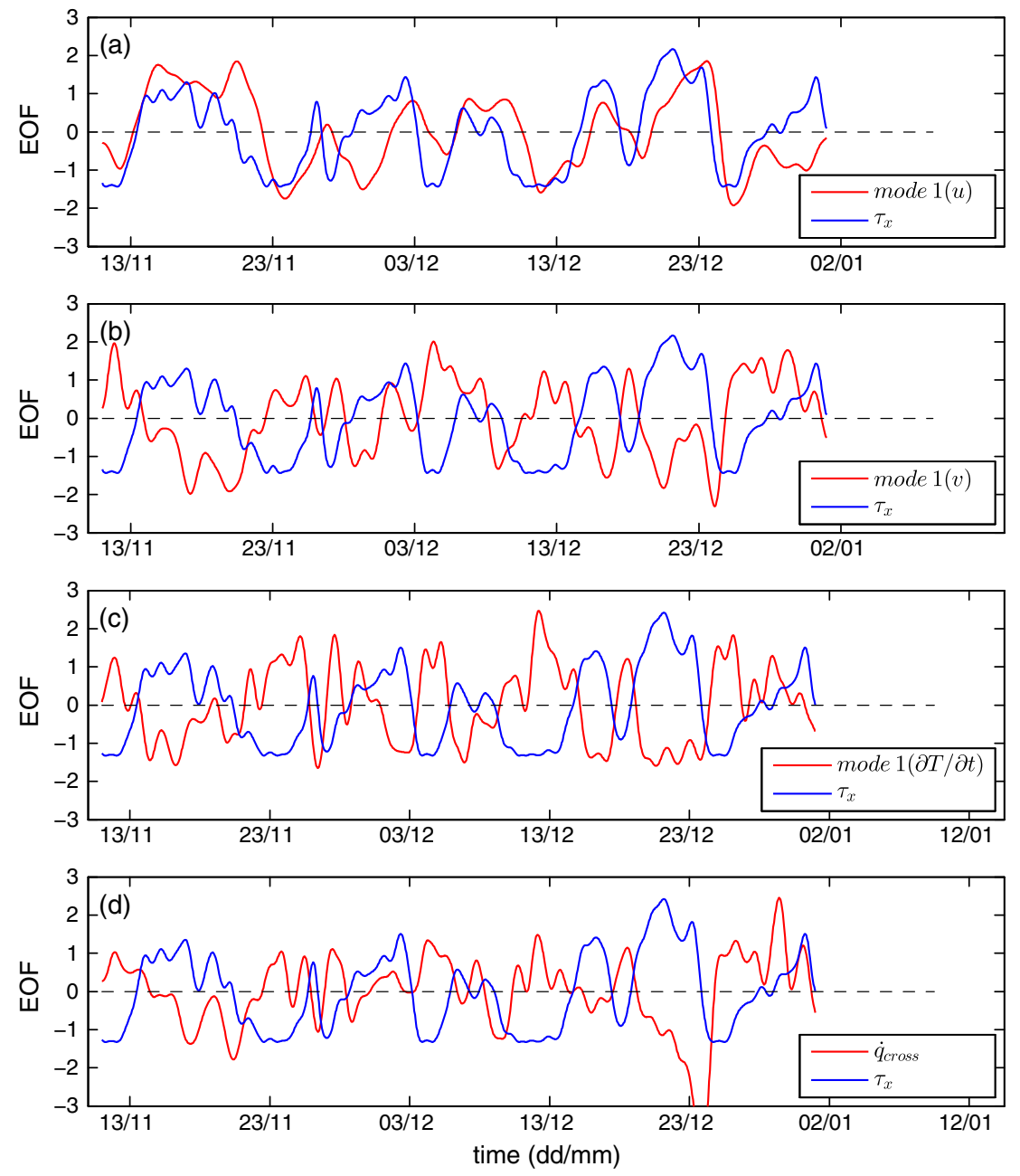

Figure 9. (a) Time series of the along-shelf wind stress (blue line) with (a) the first EOF modal amplitude of the along-shelf current, (b) with the first EOF modal amplitude of the cross-shelf velocity, (c) with the first EOF modal amplitude of the rate of temperature change $\partial T / \partial t$, and (d) with the depth integrated cross-shelf heat flux (red line), measured at M3. Note that each time series was normalized by its standard deviation. Detailed summary statistics for all sites are included in Table 2.

\subsection{Temperature Variability and Cross-Shelf Heat Fluxes}

[34] Time series of the vertical subtidal temperature variability at M3 and M5 (the two moorings where high resolution thermistor data were available) show three major cooling events (centered at $\sim 18$ November, $\sim 6$ December, and $\sim 23$ December) that occurred following periods of sustained northward flow (Figure 10). The response of temperature to winds appeared more prolonged than the along-shelf currents, with the cooling often remaining approximately 4 days after significant northward flow had ceased.

[35] The mean temperature profiles in Figure $8 \mathrm{~g}$ for the two moorings (M3 and M5) show a similar structure, although surface waters were slightly cooler on average in shore at $\mathrm{M} 3$ by $\sim 0.3^{\circ} \mathrm{C}$. The inshore site (M3) also experienced much larger temperature fluctuations (Figure 8h). The first EOF mode of the temperature structure explained $89 \%$ and $94 \%$ of the variance at M3 and M5, respectively, with somewhat larger variations near the bottom and towards the shore (Figure 8i). Given that the along-shelf winds should relate to the rate of change of temperature $\partial T / \partial t$ (not $T$ itself) [Hickey et al., 2003], the relationship between these two variables was investigated. Results from a lag correlation analysis of the along-shelf wind stress and $\partial T / \partial t$ (computed by differentiating the first EOF modal amplitude time series) gave $R=-0.78$ at M3 and $R=-0.79$ at M5, when the temperature change rates lagged the winds by $\sim 12 \mathrm{~h}$ (Table 2 ); note that the negative correlation implies that a northward wind corresponds to a cooling of the shelf region (Figure 9c).

[36] Variations in the cross-shelf heat fluxes $\dot{q}_{\text {cross }}$ (calculated via equation (12)) at M3 showed a similar response and were thus highly correlated with the local along-shelf wind stresses (Figure 9d), i.e., $R=0.6$ at a time lag of $18 \mathrm{~h}$ (Table 2). On average, the mean rates of changes of the local heat budget were minimal over this 2 month period $\left(<0.3 \times 10^{6} \mathrm{~W} \mathrm{~m}^{-1}\right)$ at the moorings, whereas the crossshelf heat fluxes from equation (12) contributed to about $2.3 \times 10^{6} \mathrm{~W} \mathrm{~m}^{-1}$ of cooling at M3 and $6.8 \times 10^{6} \mathrm{~W} \mathrm{~m}^{-1}$ of cooling at M5, approximately 3 times larger than the estimated heat input (warming) from the net surface heat fluxes (Table 3). Unfortunately, this field analysis cannot provide 
XU ET AL.: SUMMER CIRCULATION OFF NINGALOO REEF
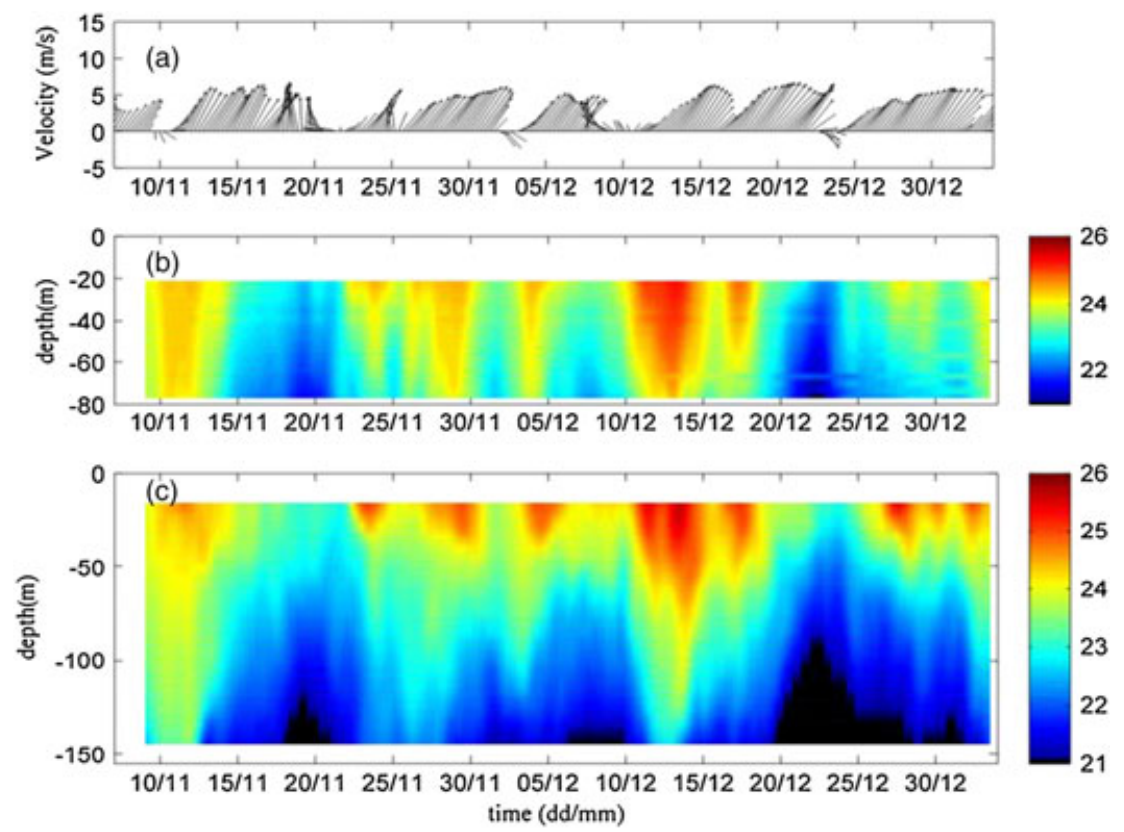

Figure 10. Time series of subtidal temperature profiles recorded at (b) site M3 and (c) site M5, with the corresponding low-pass filtered wind vectors superimposed in (a). Color bars denote the temperature in ${ }^{\circ} \mathrm{C}$.

Table 3. Estimated Terms in the Heat Budget Averaged During the Experiment Period (Expressed in $\left.10^{6} \mathrm{~W} \mathrm{~m}^{-1}\right)^{\mathrm{a}}$

\begin{tabular}{lcccc}
\hline Sites & Period & Mean Cross-Shelf Heat Flux $-\rho c_{p} \int_{-D}^{0} \tilde{\widetilde{v}} d z$ & $\begin{array}{c}\text { Mean Surface Heat } \\
\text { Flux (From NCEP }\end{array}$ & $\begin{array}{c}\text { Mean Heat Budget } \\
\text { Change Rate } \rho c_{p} \frac{d}{d t} \iint T d \forall\end{array}$ \\
\hline M3 & 11 November 2009 to 3 January 2010 & -2.3 & 1.3 & -0.1 \\
M3 & 11 November 2009 to 25 November 2009 & -2.8 & 1.1 & -0.1 \\
M5 & 11 November 2009 to 25 November 2009 & -6.8 & 2.4 & -0.3 \\
\hline
\end{tabular}

${ }^{a}$ Note that the heat flux time series at M5 were only available during the first month when the ADCP data were available.

b"NCEP" denotes model output from the National Centers for Environmental Prediction.

an estimate of the along-shelf heat fluxes, which is included in the full model analysis below.

\section{Model Results}

\subsection{Momentum Balances}

[37] Time series of the five dominant terms in the depthaveraged along-shelf momentum equation (equation (2)) are decomposed in Figure 11 for sites M2 $(50 \mathrm{~m})$ and M5 $(150 \mathrm{~m})$. Correlation coefficients between these momentum terms suggested the acceleration term $\partial U / \partial t$ was more highly correlated with the ageostophic pressure gradient ( $R=0.72$ at zero lag) than the local wind stress $(R=0.44$ at $\sim 2$ day lag) (Table 4$)$. The ageostophic pressure gradient term was moderately correlated with the local wind stresses ( $R=-0.45$ at $\sim 2$ day lag). The nonlinear advection term was almost equally correlated $(R=0.4-0.5)$ with the ageostrophic pressure gradient term, the surface wind stress, and bottom friction term. When averaged over the two month study, there was a mean (background) poleward ageostophic pressure gradient $\left(\sim 1 \times 10^{-6} \mathrm{~m} \mathrm{~s}^{-2}\right)$ that was primarily balanced by the opposing wind stress term. On average, the advection and bottom stress terms played a minimal role on the momentum balances at M2 and M5 but were episodically important (Figure 11 and Table 5).

[38] From these momentum balances, we can further examine the detailed dynamics of the circulation response that occurred during "representative" periods of sustained equatorward (northward) wind 15-21 November (hereinafter "Event 1") followed by a period of wind relaxation 21-25 November (hereinafter "Event 2") (Figure 11). Prior to Event 1, the along-shelf flow was poleward (southward), but on $\sim 15$ November, the coastal waters were accelerated northward (positive advection) due to the sustained equatorward wind. The poleward pressure gradient term subsequently grew significantly until it overcame the wind stress term on $\sim 18$ November, causing the along-shelf flow to decelerate and then reverse southwards around 21 November, thus defining the start of Event 2. During Event 2, wind stresses were weak, despite the weakening of the poleward pressure gradient; this coincided with a period of consistent poleward flow. Comparing results from both inshore (M2) and offshore stations (M5), we note that the influence of the surface wind stress term was generally much greater at M2 than at M5 due to the shallower water column, while the opposing bottom stress term was also much greater inshore at M2. The bottom stress term was negligible at the deeper mooring (M5), which 

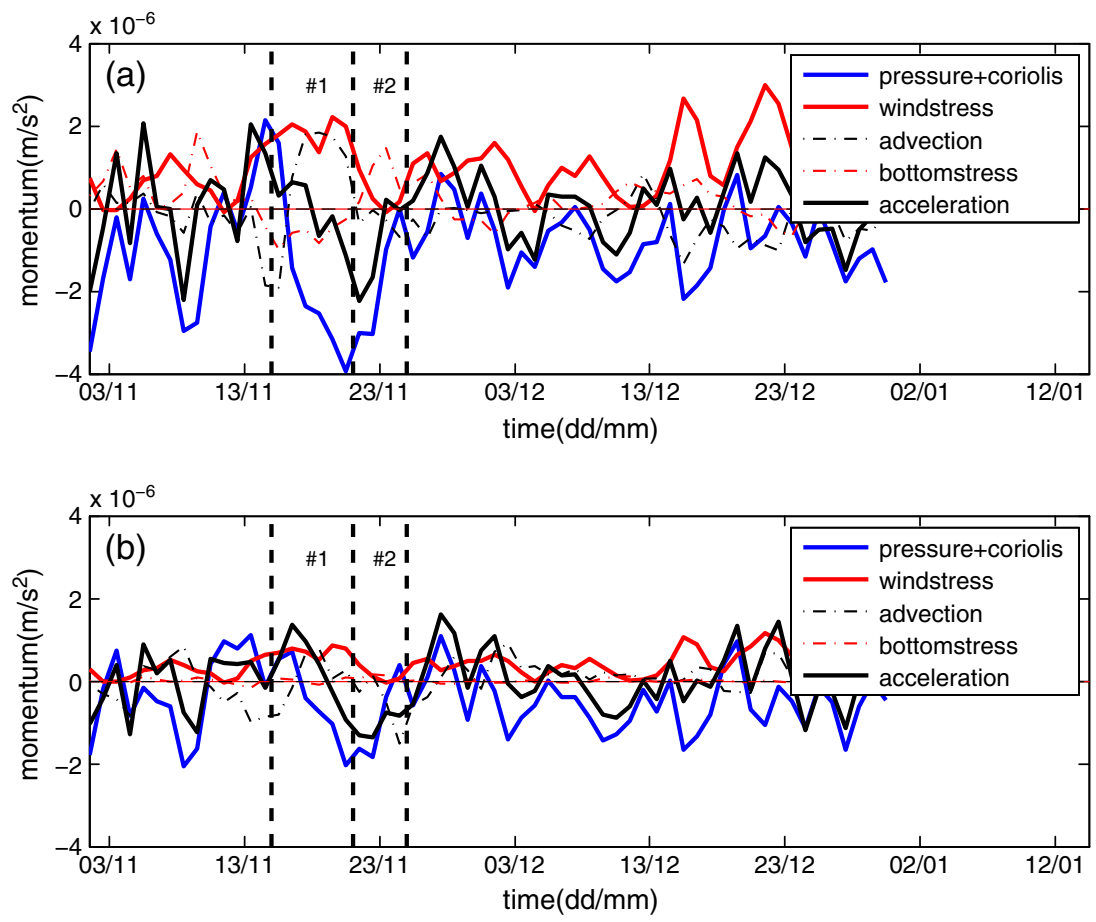

Figure 11. Time series of the depth-averaged along-shelf momentum terms at mooring sites (a) M2 and (b) M5. The upwelling event (15-21 November) and relaxation event (21-25 November) are distinguished by the three vertical dashed lines. \#1 and \#2 denote the two events that are discussed in detail in the text.

Table 4. Maximum Lag Coefficients $(R)$ Between Different Variables, as Computed From the Momentum Terms at M2 ${ }^{\mathrm{a}}$

\begin{tabular}{|c|c|c|c|c|c|}
\hline & $\partial U / \partial t$ & Advection & $-\frac{1}{D} \int_{-1}^{0} \frac{H_{z}}{\rho_{0}} \frac{\partial P}{\partial x} d \sigma-f V$ & $\tau_{x s} / D \rho_{0}$ & $-\tau_{x b} / D \rho_{0}$ \\
\hline$\partial U / \partial t$ & 1 & $0.36(8 \mathrm{~d})$ & $0.72(0 \mathrm{~d})$ & $0.44(-2 \mathrm{~d})$ & $-0.58(-1 \mathrm{~d})$ \\
\hline Advection & - & 1 & $-0.51(0 \mathrm{~d})$ & $0.39(3 \mathrm{~d})$ & $-0.46(-4 d)$ \\
\hline$-\frac{1}{D} \int \frac{H_{z}}{\rho_{0}} \frac{\partial P}{\partial x} d \sigma-f V$ & - & - & 1 & $0.45(-2 \mathrm{~d})$ & $-0.52(-2 \mathrm{~d})$ \\
\hline$\tau_{x s} / D \rho_{0}$ & - & - & - & 1 & $-0.51(0 \mathrm{~d})$ \\
\hline$-\tau_{x b} / D \rho_{0}$ & - & - & - & - & 1 \\
\hline
\end{tabular}

${ }^{\mathrm{a}}$ Time lags (in units of days) are included in the parentheses. All correlation coefficients were significant $(p<0.05)$.

Table 5. The Depth-Averaged Along-Shelf Momentum Terms Time-Averaged During the Experiment (Expressed in $\left.10^{-7} \mathrm{~m} \mathrm{~s}{ }^{-2}\right)$

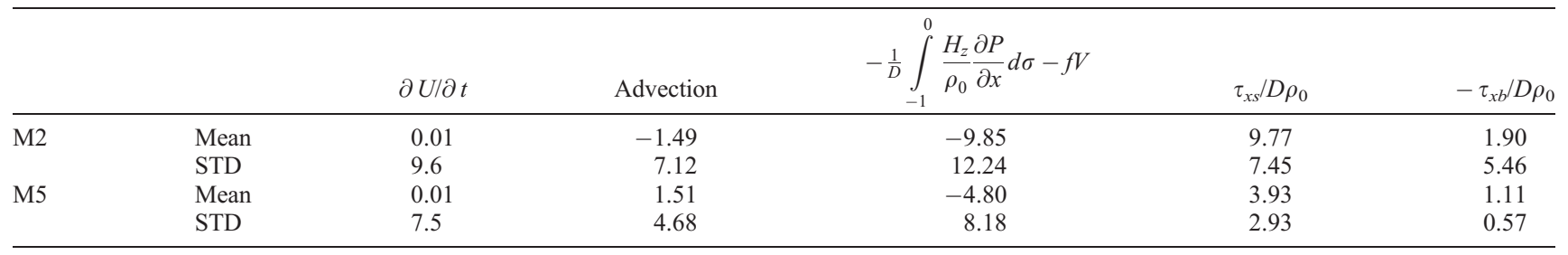

ultimately led to the stronger wind-driven currents observed at the offshore mooring M5. In addition, the results also indicated that periods of upwelling-favorable wind stresses were partially coincident with changes in the pressure gradient term, although the two terms were not strictly in phase (Figure 11).

[39] The horizontal structure of the same time-averaged momentum terms are shown in Figures 12 and 13 during both the upwelling-favorable (time average of 15-21 November, Event 1) and relaxation periods (time average of 21-25 November, Event 2). During the upwelling-favorable wind event, a southward (negative) pressure gradient acted throughout the coastal and shelf region (Figure 12a). The dominant northward (positive) driving force was the wind stress present along the entire coast (Figure 12b), which was primarily balanced by the ageostrophic pressure gradient and 


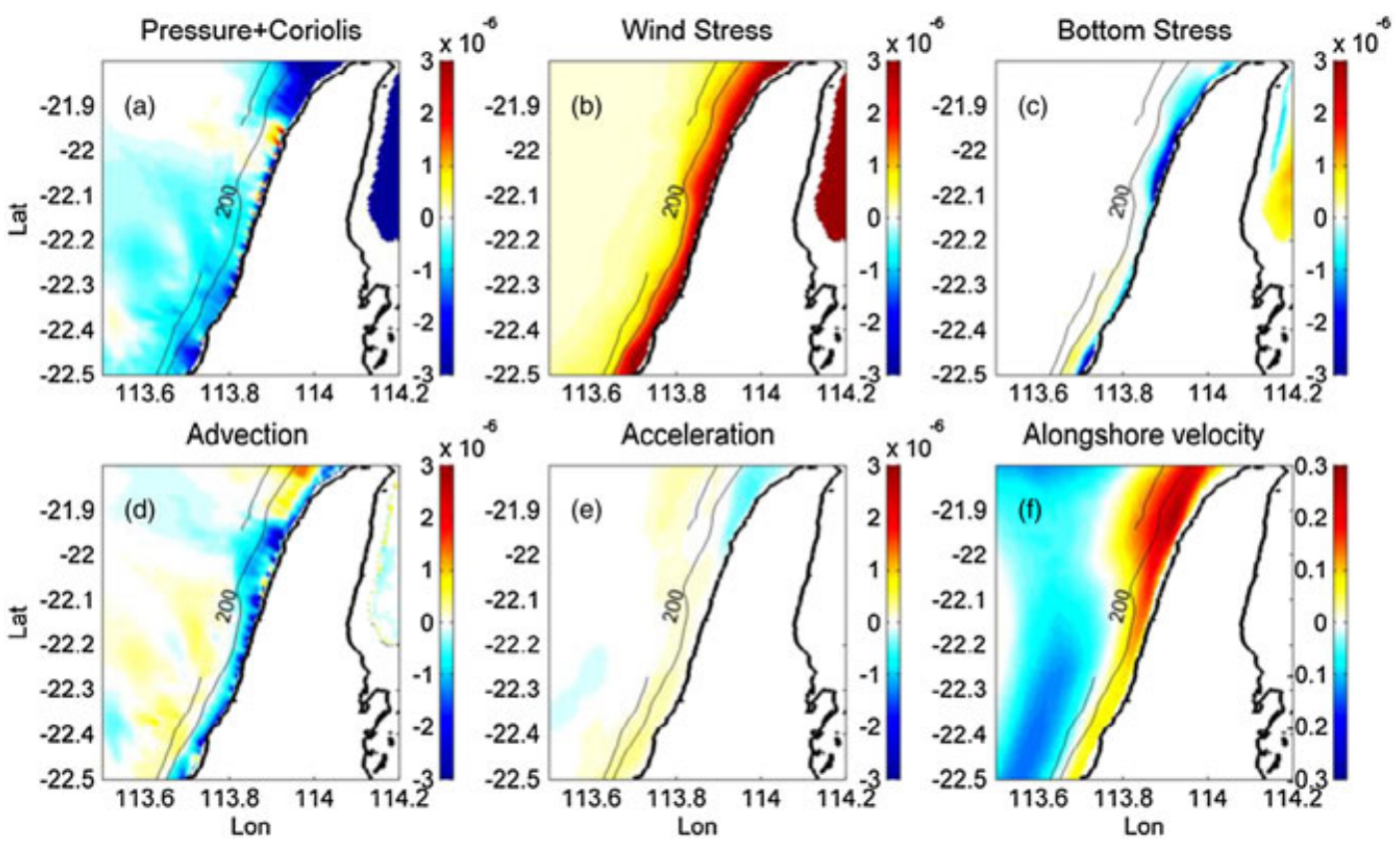

Figure 12. Spatial distribution of the depth-averaged momentum terms and along-shelf velocity during the upwelling event (average of 15-21 November). (a) ageostrophic pressure gradient; (b) surface stress term; (c) bottom stress term; (d) horizontal advection term; (e) acceleration term; and (f) along-shelf velocity.
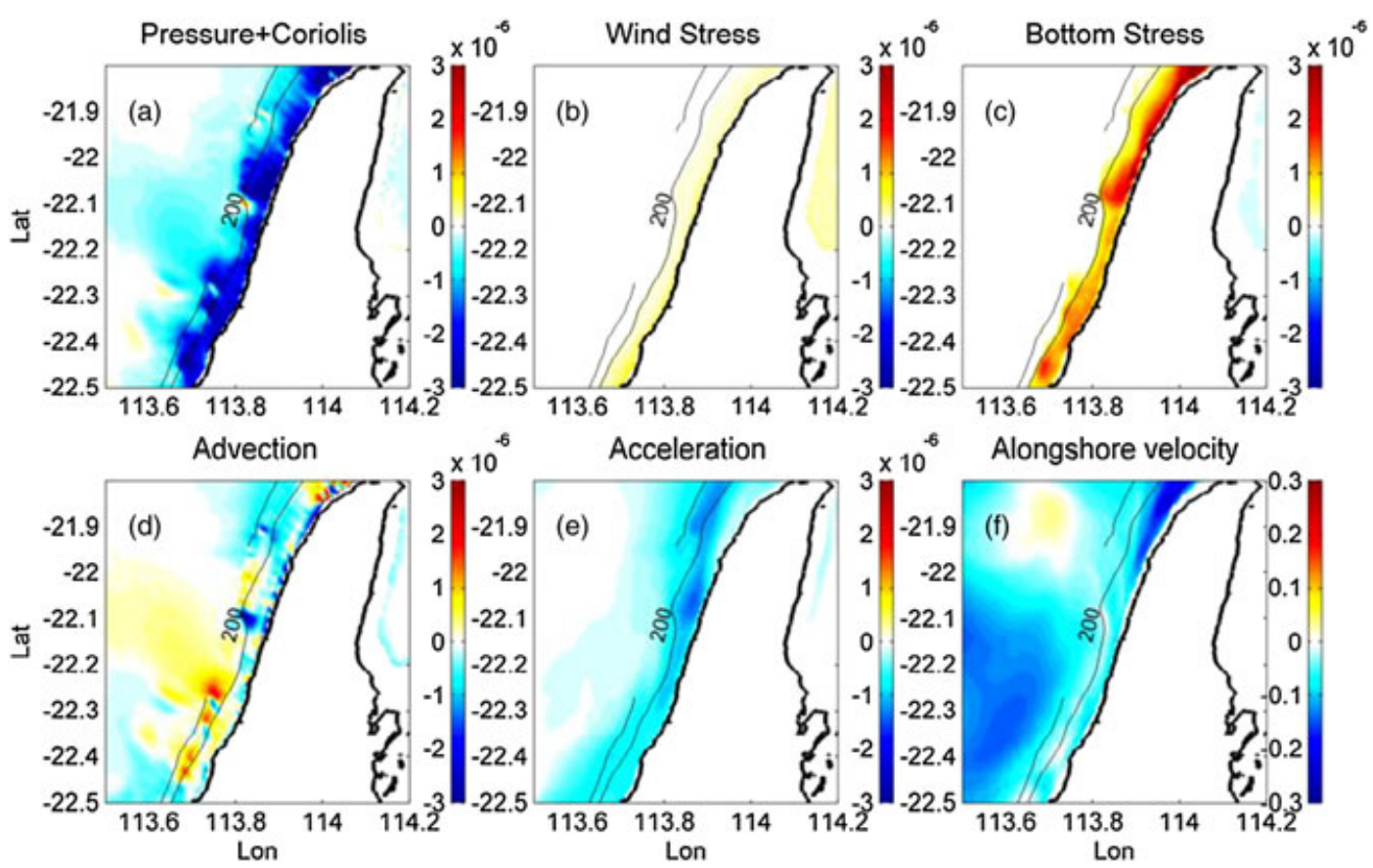

Figure 13. Spatial distribution of the depth-averaged momentum terms and along-shelf velocity during the relaxation event (average of 21-25 November). (a) ageostrophic pressure gradient; (b) surface stress term; (c) bottom stress term; (d) horizontal advection term; (e) acceleration term; and (f) alongshelf velocity.

nonlinear advection terms (Figure 12d); other terms, i.e., the bottom stress (Figure 12c), were relatively small even near the coast. This balance operated and thus generated a relatively narrow northward coastal current extending along the model domain (Figure 12f).
[40] During the relaxation event (21-25 November), the upwelling-favorable wind stresses weakened and the alongshelf current was reversed by the pressure gradient with the flow on average southward. The ageostrophic pressure gradient during this period was greater than the weakened 
northward wind stress (Figures 13a and 13b). During this period, the pressure-driven current was generally deeper and stronger than the northward wind-driven current; therefore, the bottom stress term reversed in sign to oppose the current (Figure 13c). In some regions, the nonlinear advection term was comparable in magnitude with the bottom stress (i.e., in the south), hence becoming important in balancing the pressure gradient term (Figure 13d). Overall, the net forcing resulted in a southward flow across a wide zone adjacent to the coast (Figure 13f).

[41] We do not show the equivalent analysis for the crossshelf momentum equation, given our focus is on the ageostrophic dynamics influencing the along-shelf current variability. But to summarize these results, in the cross-shelf direction, a dominant balance was observed between the cross-shelf pressure gradient term and the Coriolis term originating from the along-shelf current (not shown). All the other terms (e.g., wind stress, bottom stress, and advection) in the cross-shelf momentum balance were more than an order of magnitude smaller, suggesting the dominance of a geostrophic equilibrium in this direction.

\subsection{Upwelling and Downwelling Characteristics}

[42] We examined the response (horizontal plane and cross section) of the currents and temperature fields time-averaged over the same upwelling-favorable (15-21 November) and downwelling-favorable (21-25 November) scenarios described in the previous section. The aim was to examine the detailed upwelling and downwelling characteristics by highlighting the spatial dynamics of these scenarios. A persistent cyclonic mesoscale eddy presented offshore of the NW Cape for both periods (not shown). During upwelling, when the coastal surface temperature was $\sim 1-2^{\circ} \mathrm{C}$ cooler than offshore, there was a stronger and wider northward surface flow along the northern section of Ningaloo Peninsula than at the south section (Figures 14a and 14c). Conversely, during the
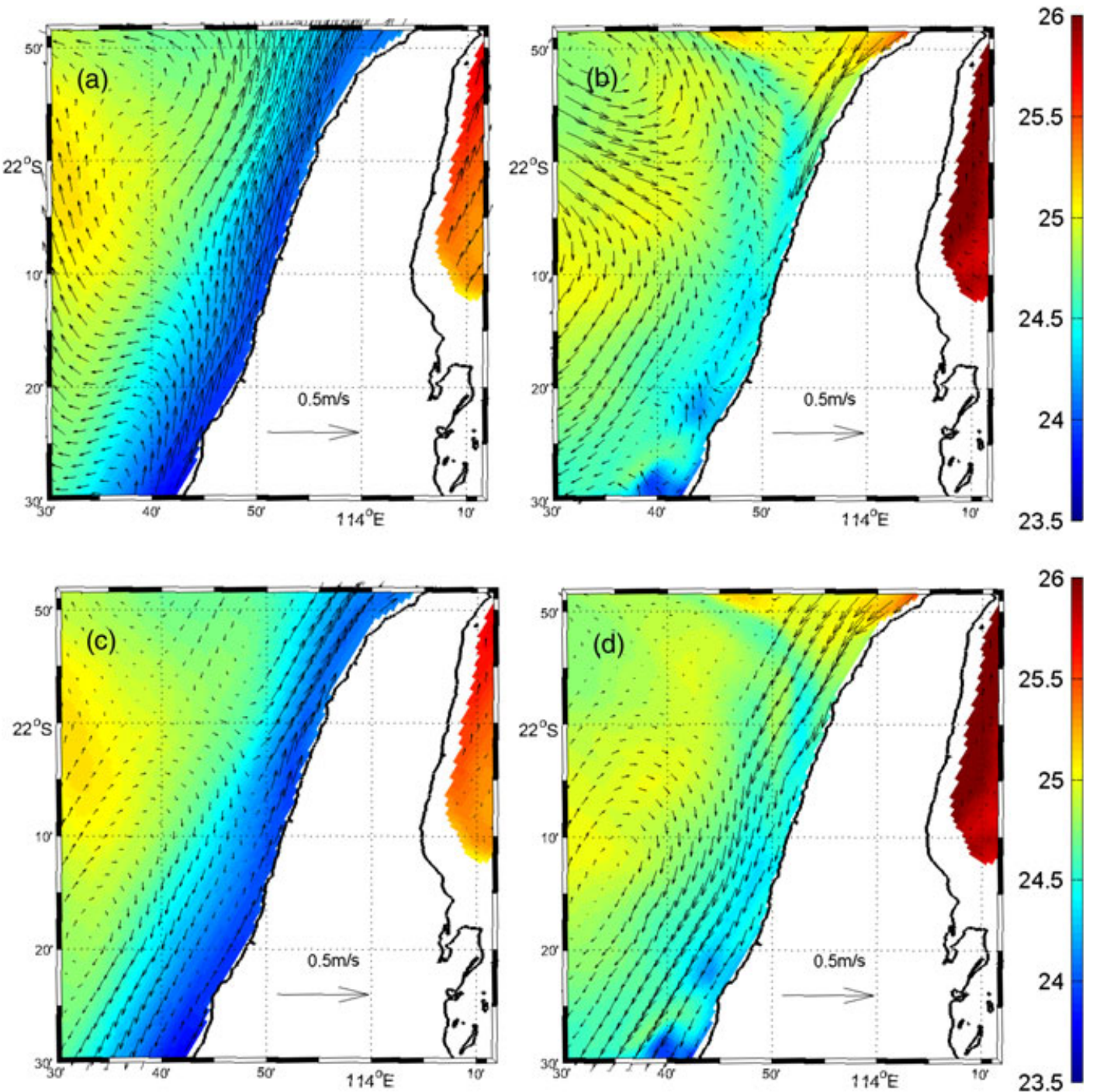

Figure 14. (a, c) The horizontal field of sea surface temperature averaged during the upwelling event (15-21 November) with (a) surface vector fields superimposed and (c) depth-averaged vector fields superimposed. (b, d) The horizontal field of sea surface temperature averaged during the downwelling event (21-25 November) with Figure 14b surface vector fields superimposed and Figure 14d depth-averaged vector fields superimposed. Note that only every 16 current vectors are shown. 
downwelling period, there was a southward flow of similar speed along the entire Ningaloo Peninsula with the surface temperature $\sim 1-2^{\circ} \mathrm{C}$ warmer than the previous period (Figures 14b and 14d). The surface velocity fields adjacent to the coast were significantly different from the depthaveraged velocity fields, particularly during the upwelling period where the depth-averaged flow on the shelf was nearly zero or weakly southwards while the surface currents were directed northwards (Figures 14a and 14c), hence consistent with the strong shear observed in the along-shelf velocity profiles (Figure 8a).

[43] Figures 15 and 16 show the temperature and velocity fields at three cross-shelf transects at the southern, central, and northern locations along the Ningaloo Peninsula (Figure 2a), time-averaged for the upwelling and downwelling periods, respectively. During the upwelling-favorable period (Event 1), the $24^{\circ} \mathrm{C}$ isotherm was elevated in all three sections and reached the surface at both the central and southern sections (Figures 15a, 15e, and 15i). The isotherm distortion and the upwelling front were confined within a $<100 \mathrm{~m}$ thick surface layer; i.e., the $23^{\circ} \mathrm{C}$ isotherm below was not significantly deflected. The northward along-shelf current (Figures 15b, $15 \mathrm{f}$, and $15 \mathrm{j}$ ) accelerated from south to north, peaking at a speed of $\sim 0.3 \mathrm{~m} \mathrm{~s}^{-1}$ in a core $\sim 10 \mathrm{~km}$ offshore in the surface $50 \mathrm{~m}$ of the water column at the northern transect. The along-shelf transport of this flow (integrating from the alongshelf velocities within a control volume extending to $15 \mathrm{~km}$ of the coast) increased from around $3000 \mathrm{~m}^{3} \mathrm{~s}^{-1}$ at the south section to roughly $90,000 \mathrm{~m}^{3} \mathrm{~s}^{-1}$ at the north section (not shown). In all transects, there was offshore (positive) flow in a near-surface layer with onshore (negative) flow beneath, although the strength varied from north to south (Figures $15 \mathrm{c}$, $15 \mathrm{~g}$, and $15 \mathrm{k}$ ). The magnitude and scale of the offshore surface flow increased towards the north, with speeds reaching $>0.1 \mathrm{~m} \mathrm{~s}^{-1}$ in a region extending $20 \mathrm{~km}$ offshore. The offshore extent of the cross-shelf flow was much greater than for the along-shelf flow. In all sections, a band of upward (positive) vertical velocity occurred within $10 \mathrm{~km}$ of the coast (Figures 15d, 15h, and 15l). During this upwelling period, there were also bands of weak downward velocities offshore at the interface between the northward and southward flow (Figures 15d, 15h, and 15l).

[44] When the wind weakened and a southward current began to dominate along the coast (Event 2), the coastal temperature at the northern section became warmer than at the southern section (Figures 16a, 16e, and 16i). There was a significant coastal depression of the isotherms, with the $24^{\circ} \mathrm{C}$ isotherm descending to depths of $100 \mathrm{~m}$ at the northern section (Figures 16a, 16e, and 16i) associated with this southward flow (Figures 16b, 16f, and 16j). This southward surface flow had a velocity of approximately $0.3 \mathrm{~m} \mathrm{~s}^{-1}$ and was confined within a deeper $(\sim 150 \mathrm{~m})$ surface layer in comparison to Event 1 for all transects (Figures 16b, 16f, and 16j). There was no evidence of surface Ekman transport (offshore flow)
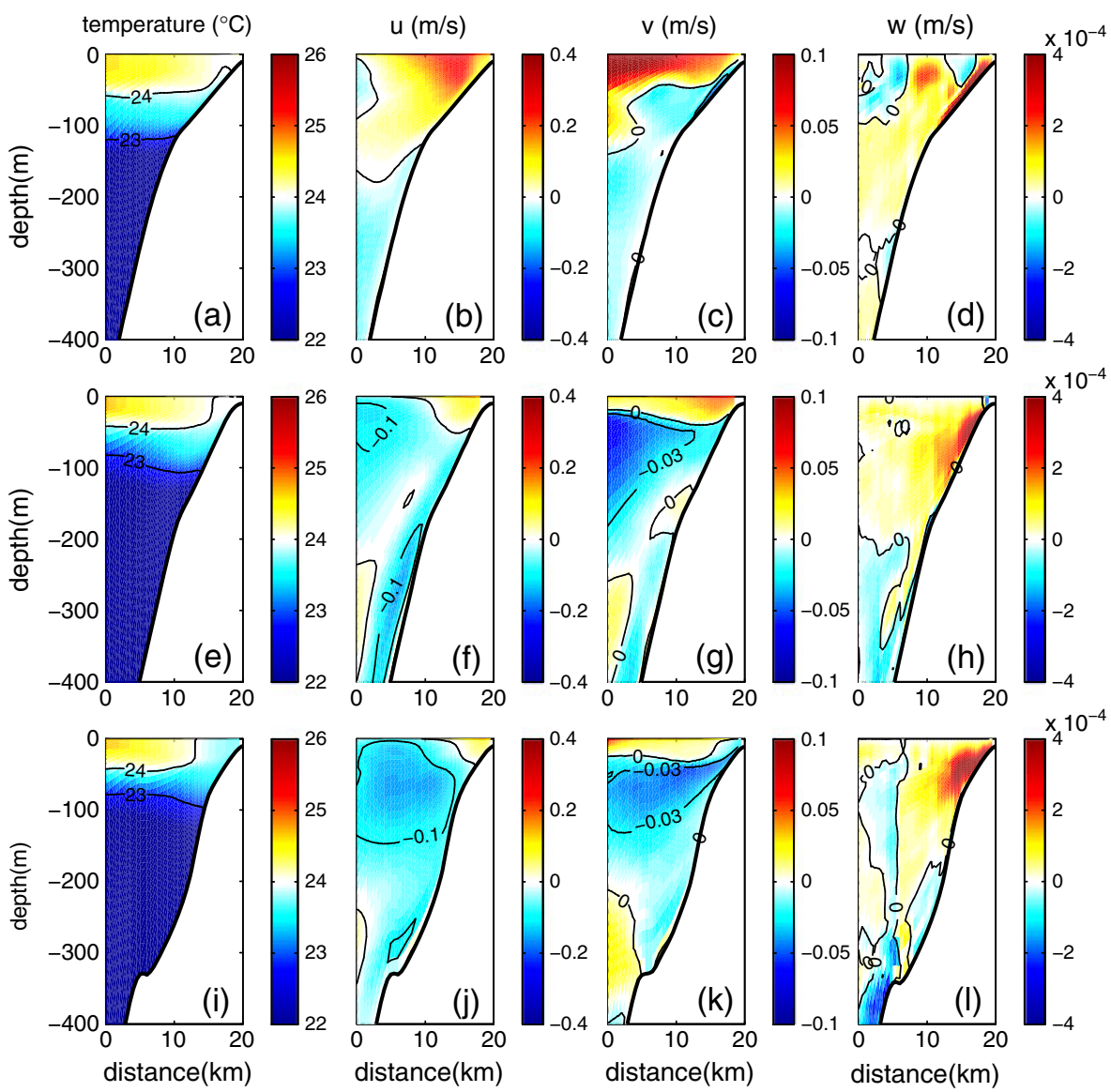

Figure 15. Temperature (a, e, i), along-shelf velocity (b, f, j), cross-shelf velocity (c, g, k), and vertical velocity distributions ( $\mathrm{d}, \mathrm{h}, \mathrm{l})$ shown for the north section (first row), the middle section (second row), and the south section (third row). All of the figures represent time-averaged results during the upwelling event between 15 and 21 November. 

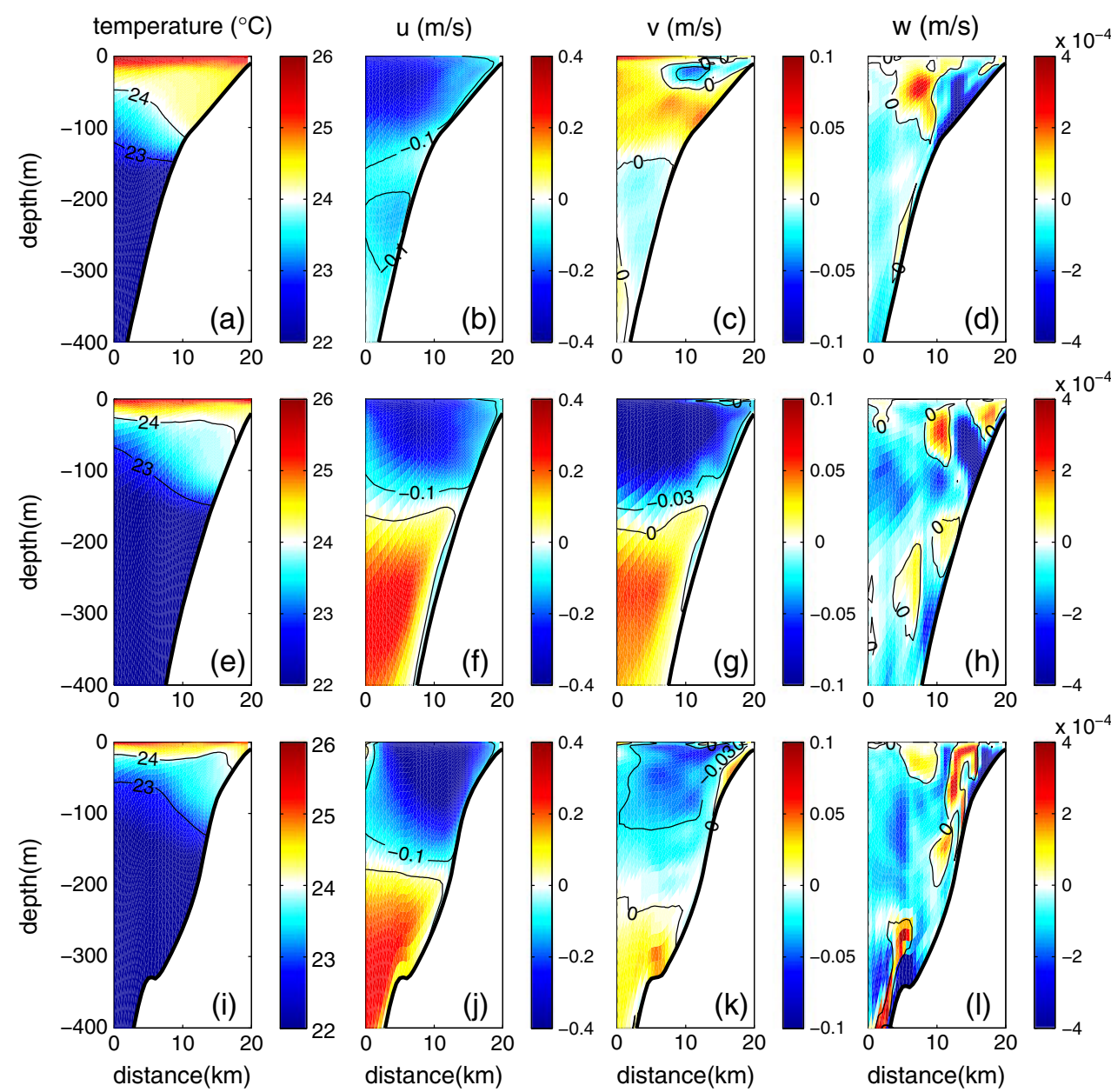

Figure 16. Temperature (a, e, i), along-shelf velocity (b, f, j), cross-shelf velocity (c, g, k), and vertical velocity distributions $(\mathrm{d}, \mathrm{h}, \mathrm{l}$ ) shown for the north section (first row), the middle section (second row), and the south section (third row). All of the figures represent time-averaged results during the downwelling event between 21 and 25 November.

at the three sections during Event 2, and vertical velocities adjacent to the coast were generally downward with the cross-shelf flow negative on the surface and positive adjacent to the bottom (downwelling).

\subsection{Cross-Shelf Transport}

[45] We compared both the daily averaged cross-shelf transport $q_{\text {cross }}$ and vertical transport $q_{\text {vert }}$ from the model, with the theoretical Ekman transport $q_{E}$ from equation (6) (Figures 17a and 17b). For comparison, the relationship between the cross-shelf transport $q_{\text {cross }}$ estimated directly from the field observations and $q_{E}$ was also evaluated (Figure 17c). To compute $q_{\text {cross }}$ using equation (4), we assumed both cases where $v_{\text {ref }}$ was equal to the depth-averaged velocity or alternatively was equal to the velocity at the base of the estimated surface boundary layer $D_{E}$. For the latter, $D_{E}$ was found to range from 30 to $50 \mathrm{~m}$; thus, for the calculations reported below, we assumed a constant value at $40 \mathrm{~m}$, which produced the best agreement between the observed and theoretical transport (see below).

[46] Both the modeled and observed $q_{\text {cross }}$ (with both the depth-averaged and $40 \mathrm{~m}$ interior velocity removed) and the modeled $q_{\text {vert }}$ were effectively equally well correlated with the theoretical Ekman transport $q_{E}$. For the $q_{\text {cross }}$, the agreement with $q_{E}$ was generally only slightly better (slope of the linear regression nearer to one) when the velocity measured $40 \mathrm{~m}$ below the surface was removed, i.e., following Lentz [1992] (Table 6); therefore, due to the consistency, only these results are summarized in Figure 17 and discussed below. These results show that the fraction of the cross-shelf transport explained by the wind-driven Ekman transport (slope of the linear regression) was nearly 1 within the uncertainty of the measurements at all sites; i.e., the presence of the poleward ageostrophic pressure gradient appeared to have little influence on this response when this interior flow was removed (Table 6). Using the model results, where vertical transport could also be quantified, we found that $q_{\text {vert }}$ was slightly better correlated with $q_{E}$, suggesting a more direct coupling to the wind than $q_{\text {cross }}$. There were periods of downwelling when the cross-shelf transport was negative, whereas the theoretical Ekman transport was still positive (given that effectively no downwelling-favorable winds occurred during the study); this implies that the downwelling was due to the pressure-driven LC and an onshore geostrophic effect rather than due to wind stresses. Finally, despite the relatively strong correlation between 

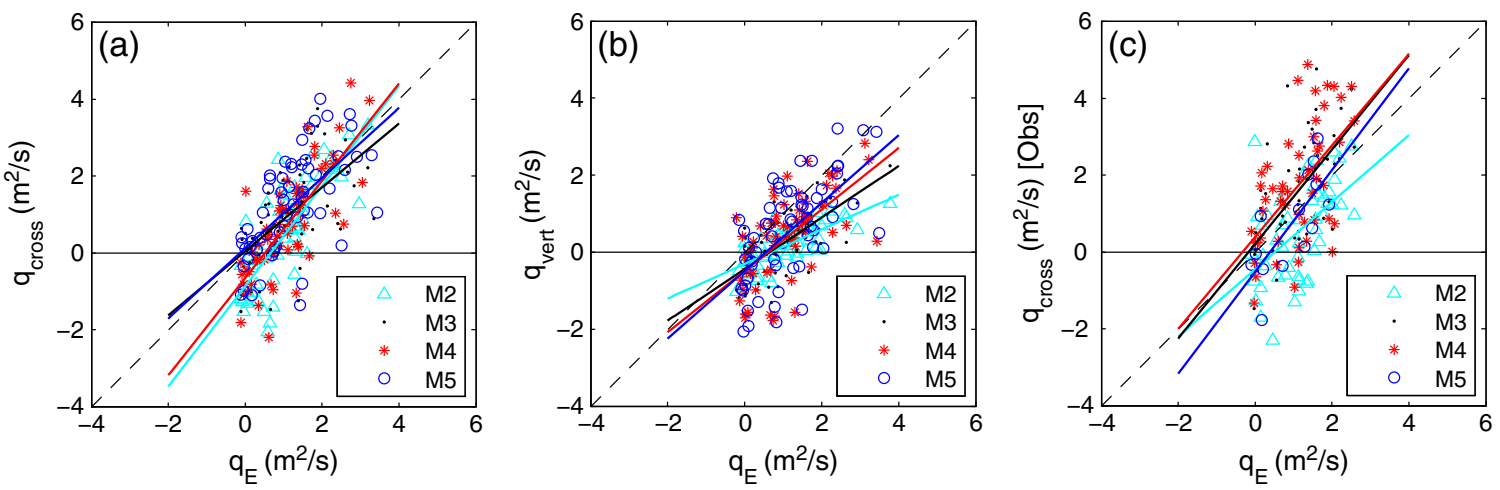

Figure 17. (a) Comparison of the theoretical Ekman transport $q_{E}$ with (a) the cross-shelf transport $q_{\text {cross }}$ computed from the model, (b) the vertical transport $q_{\text {vert }}$ computed from the model, and (c) the cross-shelf transport $q_{\text {cross }}$ computed from the field observations. The reference velocity $v_{\text {ref }}$ for Figures $17 \mathrm{a}$ and $17 \mathrm{c}$ is taken as the flow below the estimated surface boundary layer at $40 \mathrm{~m}$ depth. Note that the different markers denote data from the different mooring sites, while the colored lines denote the linear regression lines at sites with the same marker color. The black dash line represents the theoretical 1:1 relationship. A detailed summary of the regression statistics is included Table 6.

Table 6. Relationship Between the Modeled or Observed Transport $\left(q_{\text {cross }}\right.$ and $\left.q_{\text {vert }}\right)$ and the Theoretical Ekman Transport $q_{E}$, Analyzed at the Four Mooring Sites ${ }^{\mathrm{a}}$

\begin{tabular}{|c|c|c|c|c|c|c|c|c|c|c|c|c|}
\hline & \multicolumn{3}{|c|}{ M2 } & \multicolumn{3}{|c|}{ M3 } & \multicolumn{3}{|c|}{ M4 } & \multicolumn{3}{|c|}{ M5 } \\
\hline & $B 1$ & $B 0$ & $R$ & $B 1$ & $B 0$ & $R$ & $B 1$ & $B 0$ & $R$ & $B 1$ & $B 0$ & $R$ \\
\hline$q_{\mathrm{cross}, D A}$ & $0.26 \pm 0.04$ & -0.21 & 0.69 & $0.75 \pm 0.11$ & -0.37 & 0.66 & $0.56 \pm 0.07$ & -0.38 & 0.76 & $0.84 \pm 0.14$ & -0.25 & 0.62 \\
\hline$q_{\text {cross }, 40 \mathrm{~m}}$ & $1.3 \pm 0.13$ & -0.86 & 0.69 & $0.83 \pm 0.15$ & 0.04 & 0.58 & $1.26 \pm 0.15$ & -0.65 & 0.76 & $0.91 \pm 0.14$ & 0.12 & 0.62 \\
\hline$q_{\mathrm{vert}}$ & $0.45 \pm 0.05$ & -0.3 & 0.74 & $0.67 \pm 0.09$ & -0.44 & 0.69 & $0.79 \pm 0.13$ & -0.48 & 0.62 & $0.88 \pm 0.13$ & -0.48 & 0.63 \\
\hline$q_{\text {cross,DA }}\left(o b s^{\mathrm{b}}\right)$ & $0.31 \pm 0.06$ & -0.16 & 0.55 & $0.69 \pm 0.15$ & -0.1 & 0.53 & $1.03 \pm 0.22$ & 0.35 & 0.56 & $1.18 \pm 0.29$ & 0.14 & 0.76 \\
\hline$q_{\text {cross }, 40 \mathrm{~m}}\left(o b s^{\mathrm{b}}\right)$ & $0.87 \pm 0.2$ & -0.44 & 0.52 & $1.22 \pm 0.21$ & 0.21 & 0.63 & $1.19 \pm 0.25$ & 0.39 & 0.56 & $1.32 \pm 0.35$ & -0.51 & 0.72 \\
\hline
\end{tabular}

${ }^{\mathrm{a}} q_{\text {cross.DA }}$ denotes the transport with the depth-averaged flow removed, whereas $q_{\text {cross.40m }}$ denotes the transport with the interior velocity at the estimated base of the surface boundary layer ( $40 \mathrm{~m}$ below the surface) removed. $B 1$ and $B 0$ represent the slope and intercept, respectively, obtained from a linear regression between the terms, and $R$ is the correlation coefficient. Note that all correlation values were significant $(p<0.05)$, and the standard error of each regression slope is included following the plus-minus sign.

b، obs" denotes the cross-shelf transport calculated from field observations.

both $q_{\text {cross }}$ and $q_{\text {vert }}$ with $q_{E}$, there was still moderate scatter in the data (Figure 17), which is likely due to features such as coastal eddies and instabilities generated by the interaction between wind and LC (see discussion below).

[47] We finally note that upwelling from along-shelf winddriven Ekman transport appeared to be much greater than that driven by wind-stress curl (Ekman pumping) from the possible cross-shelf divergence in the coastal wind field [Capet et al., 2004]. The UCAR wind data were too coarse to accurately approximate the Ekman pumping; however, we can provide a worst case estimate by assuming that the $20 \%$ difference between the UCAR winds and the weather station measurements was solely due to physical sheltering (rather than just model error that is equally likely). By assuming this reduction over the $30 \mathrm{~km}$ scale of the UCAR data, this predicts a typical upwelling velocity of just $0.6 \mathrm{~m} \mathrm{~d}^{-1}$. This upwelling velocity is much smaller than that from the along-shelf wind driven Ekman transport (typically $>10 \mathrm{~m} \mathrm{~d}^{-1}$ ); thus, any Ekman pumping due to gradients in the coastal wind field was likely minimal.

\subsection{Coastal Heat Budget}

[48] We examined the dependence of the coastal temperature fluctuations $\partial T_{\mathrm{avg}} / \partial t$ to the three components on the right side of the heat equation (11) (Figure 18). At the southern section (Figure 18c), during upwelling events when the temperature in the control volume decreased $\left(\partial T_{\mathrm{avg}} / \partial t<0\right)$, the cross-shelf and vertical transport term $T A D V_{y z}$ tended to be comparable to $\partial T_{\mathrm{avg}} / \partial t$, suggesting that these cooling events were primarily due to vertical upwelling and the associated offshore surface transport. The surface heat flux term was relatively small and constant, having only a small influence on the coastal temperature fluctuations, as was also the alongshelf advection term $\left(T A D V_{x}\right)$. Instead, during relaxation events when the temperature in the control volume increased $\left(\partial T_{\mathrm{avg}} / \partial t>0\right)$, the heat budget was much more strongly influenced by along-shelf advection $\left(T A D V_{x}\right)$. The poleward transport of relatively warm LC water appeared to contribute most to the transient warming of the coastal waters.

[49] However, at both the central and northern sections (Figures 18a and 18b), along-shelf advection (TADV $V_{x}$ played a more important role than at the south. The upwelling at the southern part of the Ningaloo Peninsula, in turn, increased the along-shelf temperature gradient and hence the effectiveness of the along-shelf advection term. The surface heat flux term $\left(\dot{Q} / \rho c_{p} \forall\right)$ showed a small but continuous net input of heat during the two-month summer period; while this is important in driving longer time-scale changes 

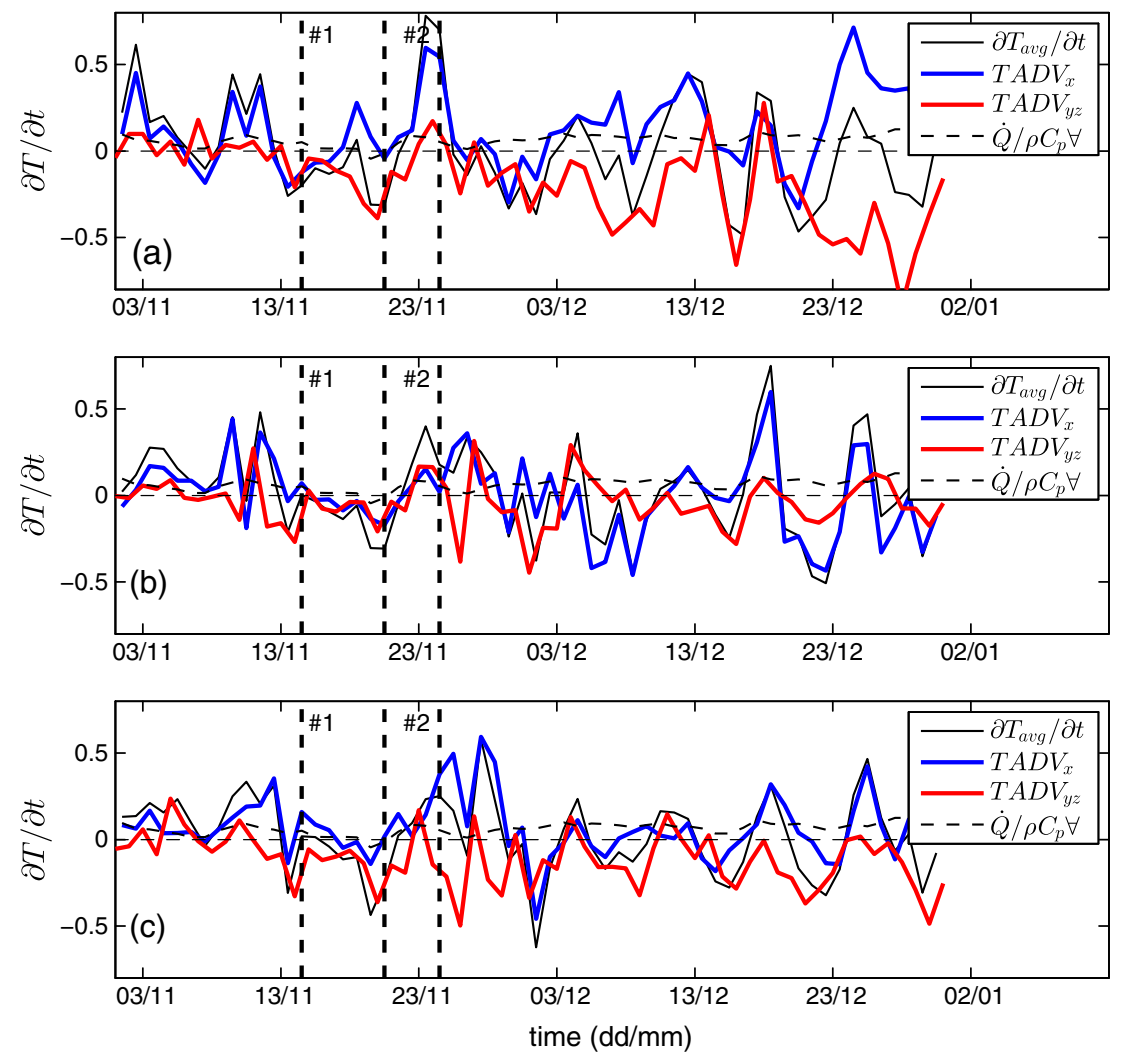

Figure 18. Time series of the rate of temperature change (in ${ }^{\circ} \mathrm{C} \mathrm{s}^{-1}$ ) within the control volume (black line), the contribution from along-shelf advection (blue line), the contribution from cross-shelf and vertical advection (red line), and the source term (black dashed line) at the (a) north section, (b) middle section, and (c) south section.

in temperature along the coast, this term had a negligible effect on the shorter (daily-weekly) time-scale temperature fluctuations that are our focus here.

\section{Discussion}

\subsection{Shelf Current Dynamics}

\subsubsection{The Role of Wind and the Along-Shelf Pressure} Gradient

[50] Analysis of the depth-averaged along-shelf momentum balance provided insight into the role that the various terms play in current variability (along-shelf and cross-shelf) on the Ningaloo shelf during summer. Wind stresses along the Ningaloo coast are of similar magnitude or larger to other classic coastal upwelling regions, such as off North and South America (Table 7). Both the field observations and numerical modeling revealed that the local along-shelf wind stress can explain much of the along-shelf current variability $(R \sim 0.7)$, when the currents lagged the wind by roughly one day. The net effect of the persistent along-shelf poleward pressure gradient in this region is that there is a threshold in the opposing wind stress that is capable of reversing the shelf circulation; results not shown indicate that (on average) this transition occurred when the northward winds were $>5 \mathrm{~m} \mathrm{~s}^{-1}$.

[51] Superimposed on the background (persistent) alongshelf ageostrophic pressure gradient was a fluctuating component that responded in part to local variability in the wind forcing (Figure 11). However, we still found that more than $80 \%(R \sim 0.4)$ of the ageostrophic pressure gradient variability

Table 7. Comparison of Stratification and Forcing Parameters for Some Major Global Upwelling Regions in Relation to the Present Observations at Different Parts of the Ningaloo Peninsula During the Study Period (November 2009-January 2010) ${ }^{\mathrm{a}}$

\begin{tabular}{|c|c|c|c|c|c|}
\hline Site & $\alpha\left(10^{-3}\right)$ & $N\left(10^{-3} \mathrm{~s}^{-1}\right)$ & $f\left(10^{-4} \mathrm{~s}^{-1}\right)$ & $\tau_{s}\left(\mathrm{~N} \mathrm{~m}^{-2}\right)$ & $B$ \\
\hline Peru $^{\mathrm{b}}$ & 8.75 & 5.85 & -0.38 & 0.11 & 1.35 \\
\hline Oregon $^{\mathrm{b}}$ & 6.7 & 14.6 & 1.03 & 0.03 & 0.95 \\
\hline Northern California $^{\mathrm{b}}$ & 5 & 7.8 & 0.91 & - & 0.43 \\
\hline North Africa ${ }^{\mathrm{b}}$ & 1.5 & 6.7 & 0.54 & - & 0.19 \\
\hline Ningaloo (North) & 18 & 6.1 & -0.55 & 0.053 & 2 \\
\hline Ningaloo (Middle) & 25 & 6 & -0.55 & 0.053 & 2.7 \\
\hline Ningaloo (South) & 25 & 5.9 & -0.55 & 0.053 & 2.7 \\
\hline
\end{tabular}

${ }^{a}$ Here $\alpha$ is the shelf slope, $N$ is the buoyancy frequency, $f$ is the Coriolis frequency, $\tau_{s}$ is the surface wind stress, and $B$ is the Burger number.

${ }^{b}$ Values from Lentz and Chapman [2004]. 
could not be explained by local along-shelf wind stresses. This is somewhat different to observations in other shelf systems with milder slopes [Fewings and Lentz, 2010; Largier et al., 1993], where fluctuations in along-shelf pressure gradients may largely oscillate directly with local wind forcing. We assume that the variability of the ageostrophic pressure gradient is a result of the more complex shelf dynamics operating in this region, i.e., from the meandering of the $\mathrm{LC}$ and offshore eddies. We note that the LC of Western Australia displays the greatest eddy kinetic energy for any eastern boundary current system globally [e.g., Feng et al., 2005].

[52] Much of the cross-shelf current variability was due to variations in the along-shelf wind stress $(R \sim 0.6)$ at a shorter lag of 0.5-1 day (Table 2). In other words, despite the presence of the background pressure gradient, we found that there was not a substantial reduction in the cross-shelf transport in response to the wind. The results also indicate that the vertical transport onto the shelf was very well-described by simple Ekman theory during upwelling events. Conversely, during downwelling periods, the poleward pressure gradient became dominant, generating an onshore flow that led to downwelling.

5.1.2. The Role of Stratification and Bottom Topography

[53] The combination of stratification and local bathymetry can have a profound influence on the structure of the wind-driven cross-shelf circulation generated on continental shelves. In the absence of stratification, upwelling can be suppressed if the time scale for vertical mixing on the shelf is much faster than the time scale for an upwelling front to develop, i.e., when the surface Ekman layer and bottom boundary layer overlap [Lentz, 2001]. Strong stratification also has the potential to increase the density gradient across the shelf, hence suppressing the further development of an upwelling front.

[54] Off the Ningaloo coast, the shelf slope is relatively steep and the stratification is seasonally dependent, with mixed layer depths ranging from $<50 \mathrm{~m}$ in summer to $>140 \mathrm{~m}$ in winter [e.g., Rousseaux et al., 2012]. The vertical structure of the cross-shelf transport during wind-driven coastal upwelling should depend on the Burger number $(B=\alpha N / f)$ [Lentz and Chapman, 2004], where $\alpha$ is the shelf slope and $N$ is the buoyancy frequency. Lentz and Chapman [2004] proposed that when $B>2$, the subsurface onshore transport of water required to balance the near-surface offshore flow is being sourced from the interior of the water column with little contribution from the frictional-influenced bottom boundary layer [Choboter et al., 2011]. A comparison of some typical parameter values at upwelling sites along North and South America is shown in Table 7; while stratification values off the Ningaloo coast in summer are not too different from typical values at other sites, the Ningaloo continental shelf is uniquely characterized by its steep shelf slope $(\sim 1 / 50$; up to 3 times steeper than the other sites). For the steep continental shelf along the Ningaloo Peninsula, the average $B$ during our summer study period was always large, with values of $3.2,2.7$, and 2 at the southern, central, and northern sections, respectively (based on the two-month averaged density field). Thus, the relatively steep bathymetry combined with the strong summer stratification suggests that the summer upwelled waters at Ningaloo are sourced from interior water on the shelf rather than from the near bed region. This source region, in turn, will likely have a strong effect on the nutrient concentrations of water supplied to Ningaloo Reef inshore [Wyatt et al., 2010].

\subsection{Heat-Budget and Coastal Cooling}

[55] The field observations showed a very strong relationship $(R=-0.89)$ between the along-shelf wind stress and the temperature variability off the Ningaloo coast (Figure 9c). Given that the along-shelf currents were also well-correlated with the wind stresses, it was unclear from the field measurements alone whether the cooling events were primarily due to either the vertical upwelling of cool water or from the equatorward advection of cooler coastal water masses from the south, or a contribution from both. The cross-shelf heat budget analysis from field observations demonstrated that the crossshelf heat advection was much larger than the surface heat inputs during these 2 months and thus contributed to a net coastal cooling. The more detailed heat budget analysis from the modeling further showed that during cooling periods $\left(\partial T_{\mathrm{avg}} / \partial t<0\right)$, the cross-shelf and vertical transport processes associated with upwelling played a more dominant role when compared to along-shelf advection of cooler water from the south. While upwelling processes generally dominated the cooling observed along the entire Ningaloo Peninsula, the along-shelf transport was increasingly important in the north. Upwelling in the south near Point Cloates brought cooler water towards the surface, with some of this upwelled water subsequently transported northwards, thereby making the along-shelf advection contribution more important. Conversely, during periods of coastal warming $\left(\partial T_{\mathrm{avg}} / \partial t>0\right)$, the cross-shelf and vertical transport processes associated with downwelling made a small contribution to warming compared to the larger contribution from the advection of warmer water from the north.

[56] Finally, we note that the upwelling events that generated the maximum coastal cooling did not necessarily coincide with the largest along-shelf wind stresses (Figure 10). For example, the coastal temperature on 23 December was significantly cooler than that on 2 January, while the wind stress was nearly the same. It appears that while northward along-shelf advection is not particularly important in controlling the rate of cooling during periods of upwelling, southward along-shelf advection during the prior period of downwelling, in turn, influences the magnitude of the temperatures that are realized during subsequent upwelling periods. In particular, when the along-shelf winds relax and the shelf warms by advection from the north, the system appears to be "reset" with a warmer initial state prior to upwelling. As a result, the coldest upwelling events were generated by the contributions from several consecutive upwelling events and were not simply attributed to the strength of the winds during the time of these upwelling events. Therefore, relying on temperature alone as an index of upwelling can be misleading in this region.

\section{Conclusions}

[57] To investigate the dynamics of the summer circulation and upwelling along the coast of Ningaloo Reef, we analyzed data from several moorings and performed numerical simulations of a 2 month study period. Both field observations and model results revealed the occurrence of transient upwelling in response to the weekly timescale fluctuations 
in wind forcing that were observed. The nested numerical models developed using ROMS were together able to accurately predict the complex current and temperature variability in this region but only when driven by a combination of local wind forcing and larger-scale forcing provided by the global scale ocean model HYCOM. Sensitivity tests stressed the importance of including the strong along-shelf geopotential gradient in the model to accurately predict the magnitude of upwelling events along this coast, a characteristic distinguishing this region from other areas globally experiencing more persistent upwelling [Chavez and Messie, 2009].

[58] The numerical model showed that the circulation response of the shelf waters to wind forcing was spatially variable, with the flow accelerating from south to north along the Ningaloo Peninsula. The accelerating equatorward flows lagged the along-shelf wind stresses by roughly 1 day and were accompanied by upwelling along the coast, characterized by vertical transport and a migration of the isotherms toward the surface. Results from an along-shelf momentum analysis indicated that the along-shelf ageostrophic pressure gradient had a strong influence on the strength of the alongshelf currents but little influence on the vertical transport rates onto the shelf. Vertical transport rates were well characterized by simple Ekman theory. However, Ekman theory could not accurately predict the structure of the cross-shelf transport along this coast as it was overlapped by background flows, such as eddies and the meandering of the offshore shelf currents. The summer stratification and relatively steep shelf of the Ningaloo coast also appeared to influence the structure of the upwelling transport, with the upwelled water being sourced from a relatively shallow depth $(\sim 100 \mathrm{~m}$; Figures $15 \mathrm{~g}$ and $15 \mathrm{k})$, consistent with the high local Burger numbers $(\sim 3)$ that occurred during the summer study.

[59] Analysis of the coastal heat budget revealed that cooling events during periods of equatorward winds were primarily due to upwelling of cooler water, rather than from along-shelf advection of cool water from the south. However, when the winds relaxed, the coastal region warmed due to the advection of warm water from the north, rather than from cross-shelf and vertical transport processes associated with downwelling. Overall, the processes observed during this study provided insight into the particular dynamics operating during the summer period, and we will investigate how shelf circulation and upwelling processes change off the Ningaloo coast in a future study focusing on the winter dynamics.
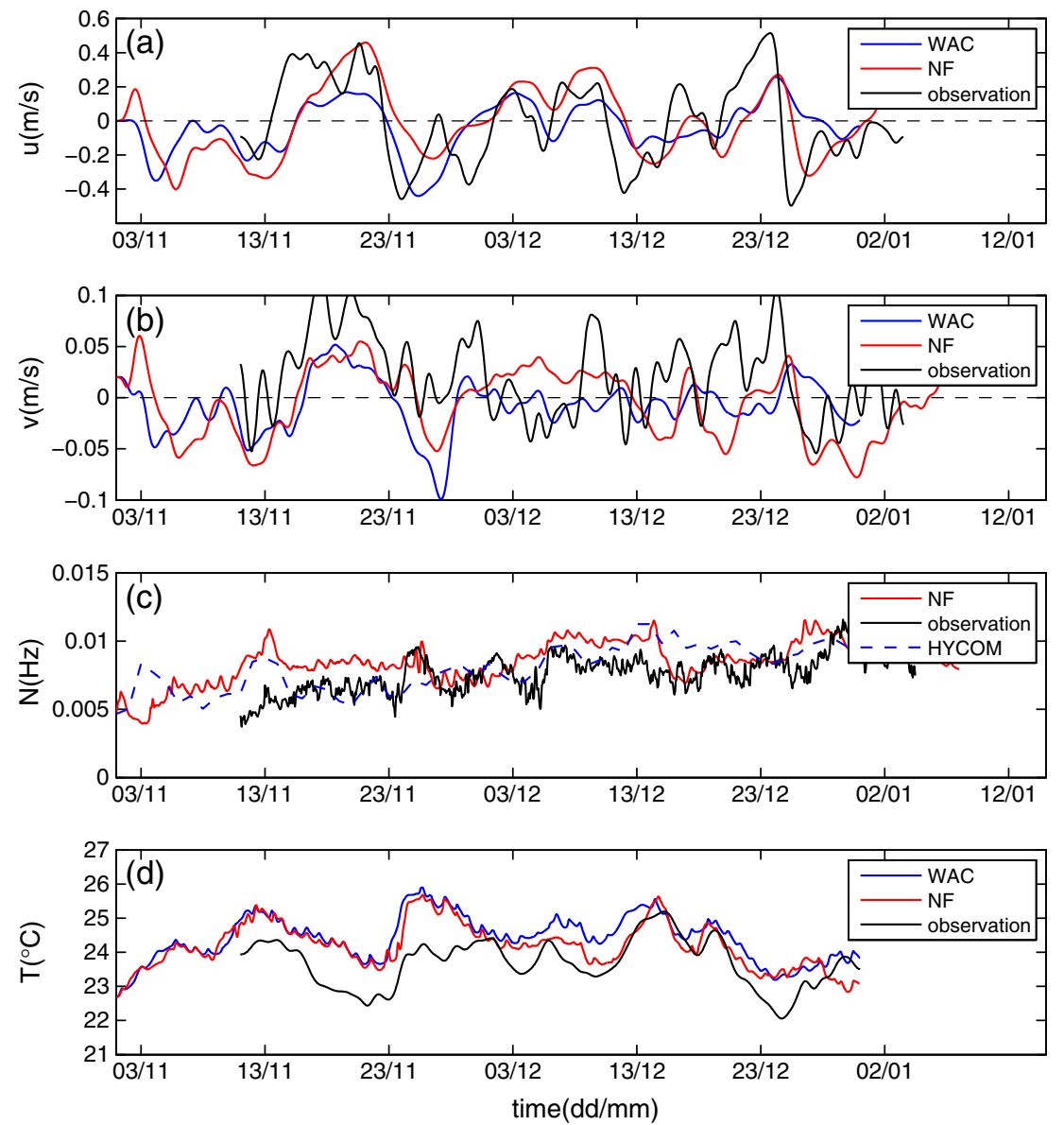

Figure 19. Time series (November 2009 to January 2010) of (a) the along-shelf surface velocity and (b) the cross-shelf velocity averaged between 20 and $40 \mathrm{~m}$ depth at the M3 mooring. (c) Comparison of the observed buoyancy frequencies with the original HYCOM and NF model results at the M5 mooring (surface $100 \mathrm{~m}$ layer). (d) Time series of the temperature (30 m below the surface) at the M3 mooring location. 


\section{Appendix A: Model Evaluation}

[60] The field observations were used to initially assess the model sensitivity to four different turbulence closure schemes in ROMS, as well as the sensitivity to the imposed wind and mesoscale ocean forcing (section A1). A detailed comparison of the final ROMS model with the field observations and discussion of the overall model performance then follows (section A2).

\section{A1. Model Sensitivity}

[61] We investigated the sensitivity of the predicted alongshelf velocity and temperature fields to four turbulence closure schemes (MY2.5, $k-\varepsilon, k-\omega$, and gen) through a series of hindcast simulations of the 2 month study period (for details of these schemes and associated empirical parameters, refer to Warner et al. 2005). The computed skill values for the depth-averaged along-shelf velocities at M3 were $0.60,0.64,0.63$, and 0.65 for MY2.5, $k-\varepsilon, k-\omega$, and gen schemes, respectively. The surface temperature (taken $20 \mathrm{~m}$ below sea surface) at the M3 was better reproduced by the $k-\omega, k-\varepsilon$, and gen closure schemes than the MY2.5 with skill values of $0.61,0.61,0.61$, and 0.56 , respectively. Thus, given the similarity in the $k-\omega, k-\varepsilon$, and gen results, we adopted the $k-\varepsilon$ scheme for all simulations.

[62] Wind speeds observed at the coastal weather station were on average slightly lower (around 20\%, possibly due to wind reduction near the coast) than the UCAR gridded wind records, despite both records being highly correlated (section 2.3). We thus investigated the sensitivity of the model results to small variations in the wind speed by comparing the observations to three model runs with the following wind variations: (1) the original UCAR wind, (2) a 10\% reduced wind speed, and (3) a 10\% enhanced wind speed. From this testing, we did not observe any improvements in the model skill, so we opted to use the original UCAR wind fields to drive the model.

[63] Finally, we ran a series of tests to investigate the sensitivity of model results to the large-scale initial conditions and boundary forcing (surface elevation and barotropic velocities) provided by HYCOM. We conducted three additional simulations where (1) we did not use HYCOM forcing to drive the WAC model, (2) we reduced the surface
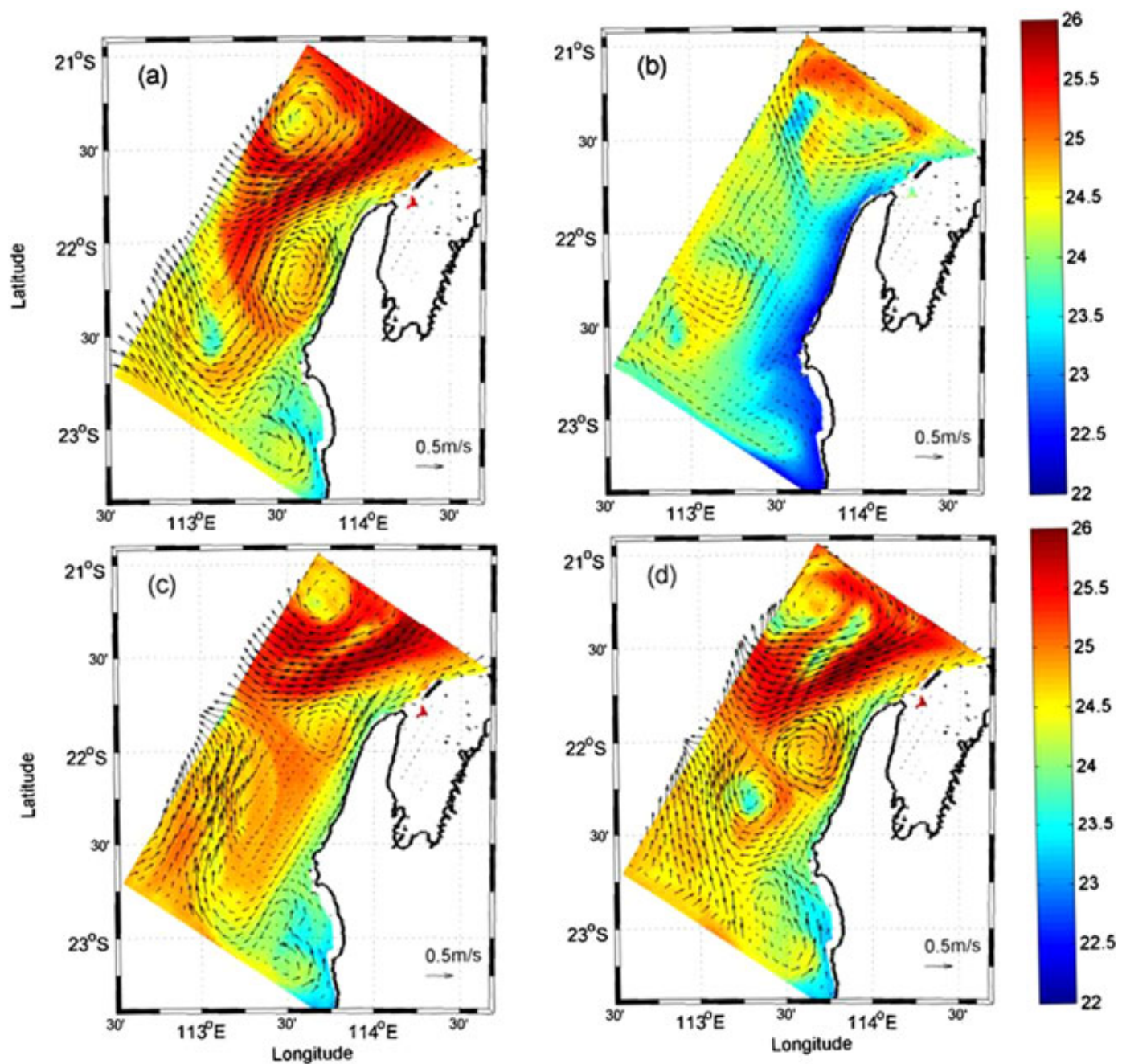

Figure 20. Surface temperature (with color bar showing ${ }^{\circ} \mathrm{C}$ ) and surface velocity fields (vectors) for the NF model domain on 18 November driven by (a) the original HYCOM forcing, (b) no HYCOM surface elevation and velocity forcing, (c) 30\% reduction in the HYCOM forcing, and (d) $10 \%$ reduction in the HYCOM forcing. See text for details. 
elevation and barotrophic velocities from HYCOM by $10 \%$, and (3) we reduced the surface elevation and barotrophic velocities from HYCOM by $30 \%$. For all simulations, we still used the same initial temperature and salinity fields from HYCOM and also retained the baroclinic velocities. As a result, the vertical shear in the three-dimensional velocity field is retained so as not to alter the thermal wind balance and hence the buoyancy adjustment. This is supported by the lack of any drift in the stratification predicted by the original HYCOM solution and the NF ROMS prediction with reduced barotropic forcing for the duration of experiment (Figure 19c).

[64] Example snapshots of surface current and temperature fields for the different scenarios on 18 November are shown in Figure 20 using the same wind forcing, which highlight several key differences. When the sea surface elevation and velocities from HYCOM were not included (Figure 20b), the model tended to significantly underestimate the southward pressure-driven LC and thus overpredicted the coastal cooling response (Figure 20a). Despite the significant benefits of driving the WAC model with the global/regional-scale model HYCOM, it appeared to overpredict the poleward LC. By reducing the large-scale surface elevation and velocities from HYCOM, the model skill of the along-shelf velocity was improved from $\sim 0.5$ (original HYCOM forcing, Figure 20d) to $\sim 0.7$ (30\% reduced HYCOM forcing, Figure 20c); this value was thus chosen for all subsequent simulations. The results of this sensitivity analysis suggest that although local wind forcing is a key driver of the shelf circulation, the dynamics are still strongly influenced by the large-scale forcing, including during summer when local wind forcing is strongest on a seasonal basis.

\section{A2. Overall Model Skill}

[65] The performance of the final nested modeling system was compared with the moored temperature and velocity measurements. An example time series from M3 is shown in Figure 19, with the performance statistics for all other shelf moorings included in Table 8. Both the coarse (WAC) and fine (NF) ROMS models reproduced the depth-averaged alongshelf current and temperature variability well. Comparison of the observed along-shelf currents (surface and bottom) with the NF model predictions showed similar performance at all sites (skill $=0.7-0.8, R M S E=0.1-0.2 \mathrm{~m} \mathrm{~s}^{-1}$, bias $\left.=0.10-0.16 \mathrm{~m} \mathrm{~s}^{-1}\right)$. The cross-shelf velocity shows less agreement with the observations, compared with the performance gain of the along-shelf velocity; however, its general trend is still captured especially during strong wind events. Note that model performance during the first half (first month) was even better (skill $=0.7-0.9$, $R M S E=0.1-0.2 \mathrm{~m} \mathrm{~s}^{-1}$, bias $<0.04 \mathrm{~m} \mathrm{~s}^{-1}$; see Table 8); this may indicate that the forward modeling was very weakly drifting away from the HYCOM initial condition in the absence of data assimilation. The model also tended to predict the pattern of observed temperature fluctuations well at these moorings (M3, M5) (Figure 19d); however, there was a small bias, with the model overpredicting the observed temperature on average by $\sim 0.6^{\circ} \mathrm{C}$, which was due to the discrepancy imposed by HYCOM. Given the stratification was reproduced well (Figure 19c), this small temperature bias is acceptable in this case.

[66] A comparison of the WAC results with the NF results showed some performance gains, but it is clear that the current and temperature variability on the shelf is significantly influenced by the larger-scale $(>>2 \mathrm{~km})$ processes resolved in both the WAC and NF models. Overall, given the nature of the complex oceanographic processes along the Ningaloo coast, with the influence of both local and remote forcing, the nested modeling system can reproduce the dominant shelf current and temperature variability along this section of the coast and provides the foundation for a more detailed analysis of the shelf processes operating along the Ningaloo Peninsula during the study.

[67] Finally, in Figure 21, we include a summary of velocity and temperature profile statistics predicted using the NF model at the mooring sites, which can be directly compared to the observations reported in Figure 8 . The model

Table 8. Model Performance Statistics Derived From a Comparison of the NF Model Results With the Field Observations at the Mooring Sites $^{\mathrm{a}}$

\begin{tabular}{|c|c|c|c|c|c|c|c|c|c|}
\hline \multirow[b]{2}{*}{ Station } & & \multicolumn{2}{|c|}{ M2 } & \multicolumn{2}{|c|}{ M3 } & \multicolumn{2}{|c|}{ M4 } & \multicolumn{2}{|c|}{ M5 } \\
\hline & & $\begin{array}{l}\text { Whole } \\
\text { Period }\end{array}$ & $\begin{array}{c}\text { First } \\
\text { Month }\end{array}$ & $\begin{array}{l}\text { Whole } \\
\text { Period }\end{array}$ & $\begin{array}{c}\text { First } \\
\text { Month }\end{array}$ & $\begin{array}{l}\text { Whole } \\
\text { Period }\end{array}$ & $\begin{array}{c}\text { First } \\
\text { Month }\end{array}$ & $\begin{array}{l}\text { Whole } \\
\text { Period }\end{array}$ & $\begin{array}{c}\text { First } \\
\text { Month }\end{array}$ \\
\hline \multirow{4}{*}{$\begin{array}{l}\text { Along-shelf } \\
\text { current } \\
\text { (surface) }\end{array}$} & Skill & 0.74 & 0.76 & 0.74 & 0.82 & 0.73 & 0.84 & - & - \\
\hline & $\operatorname{RMSE}\left[\mathrm{m} \mathrm{s}^{-1}\right]$ & 0.15 & 0.16 & 0.19 & 0.2 & 0.21 & 0.2 & - & - \\
\hline & $R$ & 0.59 & 0.6 & 0.62 & 0.7 & 0.63 & 0.76 & - & - \\
\hline & $\operatorname{Bias}\left[\mathrm{m} \mathrm{s}^{-1}\right]$ & 0.11 & 0.02 & 0.13 & -0.01 & 0.16 & -0.04 & - & - \\
\hline \multirow{4}{*}{$\begin{array}{l}\text { Along-shelf } \\
\text { current } \\
\text { (bottom) }\end{array}$} & Skill & 0.74 & 0.71 & 0.76 & 0.76 & 0.69 & 0.82 & - & - \\
\hline & RMSE $\left[\mathrm{m} \mathrm{s}^{-1}\right]$ & 0.13 & 0.15 & 0.13 & 0.16 & 0.16 & 0.14 & - & - \\
\hline & $R$ & 0.55 & 0.54 & 0.57 & 0.6 & 0.48 & 0.69 & - & - \\
\hline & $\operatorname{Bias}\left[\mathrm{m} \mathrm{s}^{-1}\right]$ & 0.1 & 0.02 & 0.1 & -0.01 & 0.13 & -0.06 & - & - \\
\hline \multirow{4}{*}{$\begin{array}{l}\text { Cross-shelf } \\
\text { current } \\
\text { (surface) }\end{array}$} & Skill & 0.49 & 0.62 & 0.54 & 0.52 & 0.52 & 0.51 & - & - \\
\hline & RMSE $\left[\mathrm{m} \mathrm{s}^{-1}\right]$ & 0.05 & 0.04 & 0.06 & 0.06 & 0.08 & 0.07 & - & - \\
\hline & $R$ & 0.22 & 0.34 & 0.45 & 0.34 & 0.27 & 0.23 & - & - \\
\hline & $\operatorname{Bias}\left[\mathrm{m} \mathrm{s}^{-1}\right]$ & -0.01 & -0.01 & -0.03 & -0.02 & -0.04 & -0.02 & - & - \\
\hline Temperature & Skill & - & - & 0.69 & 0.57 & - & - & 0.48 & 0.4 \\
\hline \multirow[t]{3}{*}{ (30 m depth) } & $\operatorname{RMSE}\left[\mathrm{m} \mathrm{s}^{-1}\right]$ & - & - & 0.81 & 0.92 & - & - & 1.2 & 1.25 \\
\hline & $R$ & - & - & 0.74 & 0.71 & - & - & 0.54 & 0.5 \\
\hline & Bias $\left[\mathrm{m} \mathrm{s}^{-1}\right]$ & - & - & 0.58 & 0.8 & - & - & 0.8 & 1.01 \\
\hline
\end{tabular}

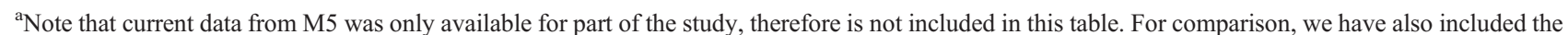
statistics based on the first month of the simulation where model agreement was even better. Correlation coefficients of over 0.3 were significant $(p<0.05)$. 

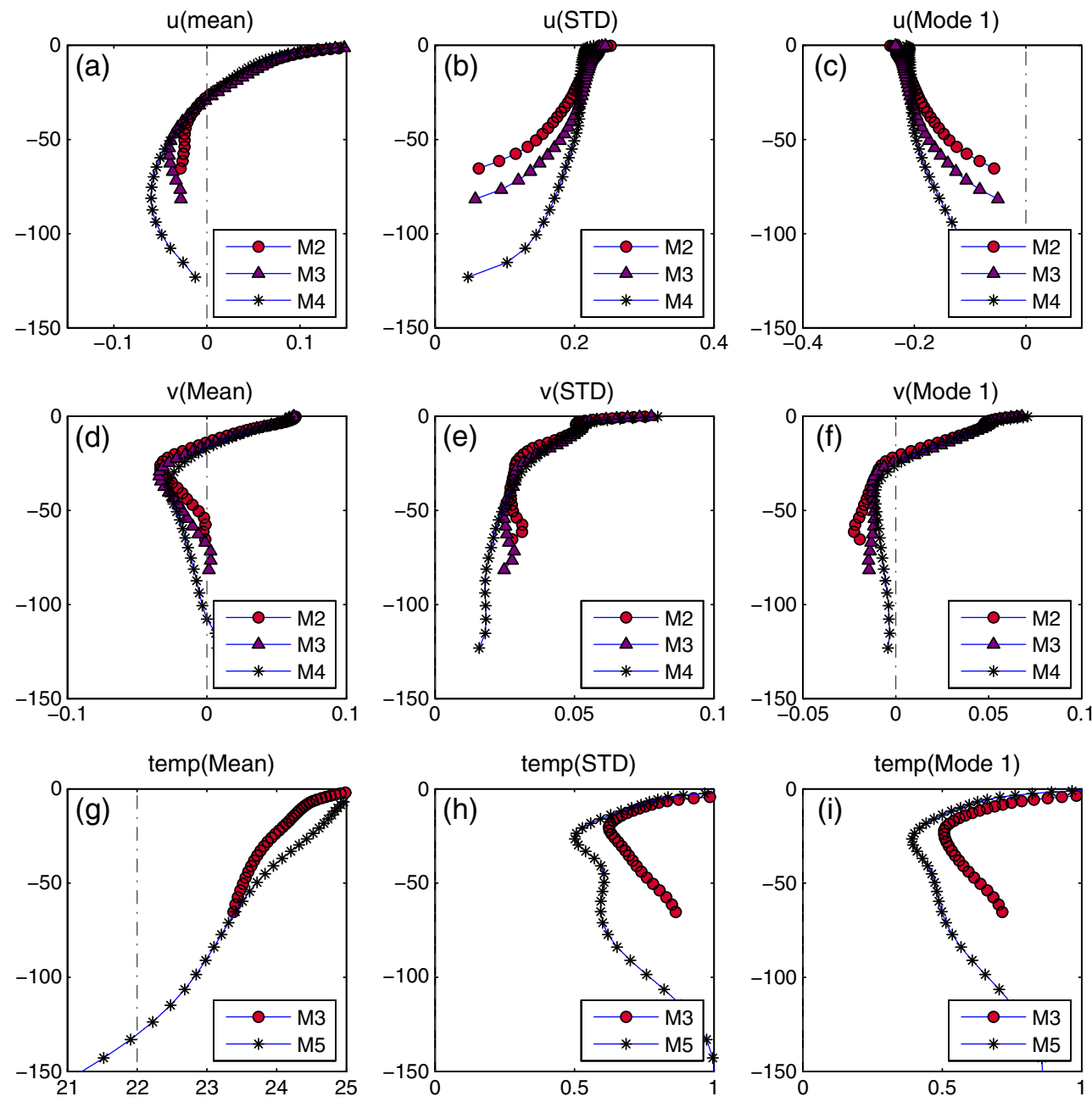

Figure 21. Statistical properties of the current and temperature profiles at the mooring sites from the hindcast NF model predictions for the field experiment period. The mean profile of the along-shelf velocity (in $\mathrm{m} \mathrm{s}^{-1}$ ), the cross-shelf velocity (in $\mathrm{m} \mathrm{s}^{-1}$ ) and temperature (in ${ }^{\circ} \mathrm{C}$ ) are shown in the first column $(\mathrm{a}, \mathrm{d}, \mathrm{g}$ ), respectively; profiles of the standard deviation are shown in the second column (b, e, h); the vertical structure of the first EOF mode is shown in the third column (c, $\mathrm{f}, \mathrm{i})$. Note that the EOF modes were multiplied by the square root of the variance.

generally captures both the observed mean structure and profile variability of the velocities (along-shore and cross-shore) and temperature well. Key features include the reproduction of a strongly sheared mean along-shelf velocity profile with a zero crossing near $\sim 30 \mathrm{~m}$ depth and a subsurface maximum that increases offshore but is $\sim 75 \mathrm{~m}$ deep at the M4 site, where the peak poleward (negative) flow reaches $\sim 0.1 \mathrm{~m}$ $\mathrm{s}^{-1}$ (Figures $8 \mathrm{a}$ and 21a). Both the variability (standard deviation) and first EOF mode of the along-shelf velocity profiles increase to $\sim 0.2 \mathrm{~m} \mathrm{~s}^{-1}$ near the surface and approach zero near the bottom, albeit there are smaller near-surface differences between sites relative to the observations (Figures $8 \mathrm{~b}$, $8 \mathrm{c}, 21 \mathrm{~b}$, and 21c). The modeled mean cross-shelf velocity profile also shows a region of offshore flow near the surface with a subsurface onshore flow maximum in the interior of the water column $(\sim 30-40 \mathrm{~m}$ below the surface)

(Figure 21d). The observations (Figure 8d) are similar; however, the onshore flow at M4 occurs somewhat deeper in the water column. The modeled mean temperature profiles in Figure $21 \mathrm{~g}$ are very similar to the observations (Figure 8g), with cooler near-surface waters at the inshore site M3. The modeled temperature variability (standard deviation) and first EOF mode also display very similar trends with larger fluctuations inshore at M3 and increasing towards the bottom to values of $\sim 0.7^{\circ} \mathrm{C}$ (Figures $8 \mathrm{~h}, 8 \mathrm{i}, 21 \mathrm{~h}$, and 21i). We note, however, that the model predicts a rapid rise in the magnitude of temperature fluctuations close to the surface (within $\sim 20 \mathrm{~m}$ ); while data from the highest thermistors at M5, located $\sim 20-40 \mathrm{~m}$ below the surface, show some increase consistent with the model, there is no data available to evaluate the relatively large $\left(\sim 1^{\circ} \mathrm{C}\right)$ variations that are predicted. These very near-surface temperature fluctuations are likely due to variations in surface heating/cooling.

[68] Acknowledgments. This work was supported by Australian Research Council Discovery Grant \#DP0985221 as well as a grant from the Western Australia Marine Science Institution to R.B. We are grateful for the extensive comments from three anonymous reviewers who greatly improved the manuscript.

\section{References}

Allen, J. S. (1980), Models of wind-driven currents on the continental-shelf, Аnпu. Rev. Fluid Mech., 12, 389-433. 


\section{XU ET AL.: SUMMER CIRCULATION OFF NINGALOO REEF}

Allen, J. S., and R. L. Smith (1981), On the dynamics of wind-driven shelf currents, Philos. Trans. R. Soc. Lond. Ser. A-Math. Phys. Eng. Sci., 302(1472), 617-634.

Allen, J. S., P. A. Newberger, and J. Federiuk (1995), Upwelling circulation on the Oregon continental-shelf. 1. Response to idealized forcing, J. Phys. Oceanogr., 25(8), 1843-1866.

Beardsley, R. C., R. Limeburner, and L. K. Rosenfeld (1985), Introduction to the CODE-2 moored array and large-scale data report, Woods Hole Oceanographic Institution.

Beckmann, A., and D. B. Haidvogel (1993), Numerical simulation of flow around a tall isolated seamount. Part 1: Problem formulation and mode accuracy, J. Phys. Oceanogr., 23(8), 1736-1753.

Blumberg, A. F., and G. L. Mellor (1987), A description of a threedimensional coastal ocean circulation model, in Three-Dimensional Coastal Ocean Models, Coastal Estuarine Sci., 4, 208

Capet, X. J., P. Marchesiello, and J. C. McWilliams (2004), Upwelling response to coastal wind profiles, Geophys. Res. Lett., 31(13), doi:10.1029/2004g1020123.

Cervantes, B. T. K., and J. S. Allen (2006), Numerical model simulations of continental shelf flows off northern California, Deep-Sea Res. Part II-Top. Stud. Oceanogr., 53(25-26), 2956-2984.

Chapman, D. C. (1985), Numerical treatment of cross-shelf open boundaries in a barotropic coastal ocean model, J. Phys. Oceanogr., 15(8), $1060-1075$.

Chassignet, E. P., H. E. Hurlburt, O. M. Smedstad, G. R. Halliwell, P. J. Hogan, A. J. Wallcraft, R. Baraille, and R. Bleck (2007), The HYCOM (HYbrid Coordinate Ocean Model) data assimilative system, J. Mar. Syst., 65(1-4), 60-83.

Chavez, F. P., and M. Messie (2009), A comparison of eastern boundary upwelling ecosystems, Prog. Oceanogr., 83(1-4), 80-96.

Choboter, P. F., D. Duke, J. P. Horton, and P. Sinz (2011), Exact solutions of wind-driven coastal upwelling and downwelling over sloping topography, J. Phys. Oceanogr., 41(7), 1277-1296.

Church, J. A., G. R. Cresswell, and J. S. Godfrey (1989), The Leeuwin Current, in Poleward Flows on Eastern Ocean Boundaries. Lecture notes on Coastal and Estuarine studies, edited by S. J. Neshyba, M. C.N. K., R. L., Smith, and R. T. Barber, pp. 230-252, Springer-Verlag, New York.

Cresswell, G. R., and T. J. Golding (1980), Observations of a south-flowing current in the southeastern Indian Ocean, Deep Sea Res. Part A, 27(6), $449-466$

Cresswell, G. R., and J. L. Peterson (1993), The Leeuwin Current South of Western Australia, Aust. J. Mar. Freshwater Res., 44(2), 285-303.

Dever, E. P. (1997), Wind-forced cross-shelf circulation on the Northern California shelf, J. Phys. Oceanogr., 27(8), 1566-1580.

Dever, E. P., and S. J. Lentz (1994), Heat and salt balances over the northern california shelf in winter and spring, J. Geophys. Res. Oceans., 99(C8), 16001-16017.

Emery, W. J., and R. E. Thomson (2001), Data Analysis Methods in Physical Oceanography, 2nd and rev. ed., xvi, pp. 638, Elsevier, Amsterdam; New York.

Fairall, C. W., E. F. Bradley, D. P. Rogers, J. B. Edson, and G. S. Young (1996), Bulk parameterization of air-sea fluxes for Tropical Ocean Global Atmosphere Coupled Ocean Atmosphere Response Experiment, J. Geophys. Res. Oceans., 101(C2), 3747-3764.

Feng, M., G. Meyers, A. Pearce, and S. Wijffels (2003), Annual and interannual variations of the Leeuwin Current at 32 degrees S, J. Geophys. Res. Oceans., 108(C11), 21.

Feng, M., S. Wijffels, S. Godfrey, and G. Meyers (2005), Do eddies play a role in the momentum balance of the Leeuwin Current?, J. Phys. Oceanogr., 35(6), 964-975.

Fewings, M. R., and S. J. Lentz (2010), Momentum balances on the inner continental shelf at Martha's Vineyard Coastal Observatory, J. Geophys. Res. Oceans., 115, doi:10.1029/2009jc005578.

Flather, R. A. (1976), A tidal model of the northwest European continental shelf, Memoires de la Societe Royale de Sciences de Liege, 10(6), 141-164.

Gan, J. P., and J. S. Allen (2002), A modeling study of shelf circulation off northern California in the region of the Coastal Ocean Dynamics Experiment 2. Simulations and comparisons with observations, J. Geophys. Res. Oceans., 107(C11), doi:3184.

Gersbach, G. H., C. B. Pattiaratchi, G. N. Ivey, and G. R. Cresswell (1999), Upwelling on the south-west coast of Australia-Source of the Capes Current?, Cont. Shelf Res., 19(3), 363-400.

Godfrey, J. S., and K. R. Ridgway (1985), The large-scale environment of the poleward-flowing Leeuwin Current, Western Australia: Longshore steric height gradients, wind stresses and geostrophic flow, J. Phys. Oceanogr., $15(5), 481-495$.

Haidvogel, D. B., et al. (2008), Ocean forecasting in terrain-following coordinates: Formulation and skill assessment of the Regional Ocean Modeling System, J. Comput. Phys., 227(7), 3595-3624.

Haney, R. L. (1991), On the pressure gradient force over steep topography in sigma coordinate ocean models, J. Phys. Oceanogr., 21(4), 610-619.
Hanson, C. E., C. B. Pattiaratchi, and A. M. Waite (2005), Sporadic upwelling on a downwelling coast: Phytoplankton responses to spatially variable nutrient dynamics off the Gascoyne region of Western Australia, Cont. Shelf Res., 25(12-13), 1561-1582.

Hickey, B. M. E. L. Dobbins, and S. E. Allen (2003), Local and remote forcing of currents and temperature in the central Southern California Bight, J. Geophys. Res. Oceans., 108(C3), doi:10.1029/2000jc000313.

Large, W. G., and S. Pond (1981), Open ocean momentum flux measurements in moderate to strong winds, J. Phys. Oceanogr., 11(3), 324-336.

Largier, J. L., B. A. Magnell, and C. D. Winant (1993), Subtidal circulation over the northern California shelf, J. Geophys. Res. Oceans., 98(C10), 18147-18179.

Lentz, S. J. (1992), The surface boundary layer in coastal upwelling regions, J. Phys. Oceanogr., 22(12), 1517-1539.

Lentz, S. J. (2001), The influence of stratification on the wind-driven crossshelf circulation over the North Carolina shelf, J. Phys. Oceanogr., 31(9), 2749-2760.

Lentz, S. J., and D. C. Chapman (2004), The importance of Nonlinear crossshelf momentum flux during wind-driven coastal upwelling, J. Phys. Oceanogr., 34(11), 2444-2457.

Lowe, R. J., G. N. Ivey, R. M. Brinkman, and N. J. Jones (2012), Seasonal circulation and temperature variability near the North West Cape of Australia, J. Geophys. Res. Oceans, doi:10.1029/2011jc007653.

Marchesiello, P., and P. Estrade (2010), Upwelling limitation by onshore geostrophic flow, J. Mar. Res., 68(1), 37-62.

Marchesiello, P., J. C. McWilliams, and A. Shchepetkin (2001), Open boundary conditions for long-term integration of regional oceanic models, Ocean Model., 3(1-2), 1-20.

Marchesiello, P., J. C. McWilliams, and A. Shchepetkin (2003), Equilibrium structure and dynamics of the California Current System, J. Phys. Oceanogr., 33(4), 753-783.

Martinho, A. S., and M. L. Batteen (2006), On reducing the slope parameter in terrain-following numerical ocean models, Ocean Model., 13(2), $166-175$.

Melton, C., L. Washburn, and C. Gotschalk (2009), Wind relaxations and poleward flow events in a coastal upwelling system on the central California coast, J. Geophys. Res. Oceans., 114, doi:10.1029/2009jc005397.

Mesias, J. M., R. P. Matano, and P. T. Strub (2003), Dynamical analysis of the upwelling circulation off central Chile, J. Geophys. Res. Oceans. 108(C3), doi:10.1029/2001JC001135

Meuleners, M. J., C. B. Pattiaratchi, and G. N. Ivey (2007), Numerical modelling of the mean flow characteristics of the Leeuwin Current System, Deep-Sea Res. Part II-Top. Stud. Oceanogr., 54(8-10), 837-858.

Orlanski, I. (1976), A simple boundary condition for unbounded hyperbolic flows, J. Comput. Phys., 21, 251-269.

Richman, J., and A. Badan-Dangon (1983), Mean heat and momentum budgets during upwelling for the coastal waters off northwest Africa, J. Geophys. Res. Oceans. Atmos., 88(NC4), 2626-2632.

Rousseaux, C., R. J. Lowe, M. Feng, A. Waite, and P. Thompson (2012), The role of the Leeuwin Current and mixed layer depth on the autumn phytoplankton bloom off Ningaloo Reef, Western Australia, Cont. Shelf Res, doi:10.1016/j.csr.2011.10.010.

Saha, S., et al. (2010), The NCEP climate forecast system reanalysis, Bull. Amer. Meteorol. Soc., 91(8), 1015-1057.

Shchepetkin, A. F., and J. C. McWilliams (2003), A method for computing horizontal pressure-gradient force in an oceanic model with a nonaligned vertical coordinate, J. Geophys. Res. Oceans., 108(C3), 34.

Shchepetkin, A. F., and J. C. McWilliams (2009), Ocean forecasting in terrain-following coordinates: Formulation and skill assessment of the regional ocean modeling system (vol 227, pg 3595, 2008), J. Comput. Phys., 228(24), 8985-9000.

Simpson, C. J., and R. J. Masini (1986), Tide and seawater temperature data from the Ningaloo Reef Tract, Western Australia, and the implications for mass spawning. Rep., Department of Conservation and Environment Bulletin 253, Perth

Smagorinsky, J. (1963), General circulation experiments with the primitive equations, Monthly Weather Review, 91(3), 99-164.

Smith, R. L., A. Huyer, J. S. Godfrey, and J. A. Church (1991), The Leeuwin Current off Western Australia, 1986-1987, J. Phys. Oceanogr., 21(2), 323-345

Spall, M. A., and W. R. Holland (1991), A nested primitive equation model for oceanic applications, J. Phys. Oceanogr., 21(2), 205-220.

Taebi, S., R. J. Lowe, C. B. Pattiaratchi, G. N. Ivey, G. Symonds, and R. Brinkman (2011), Nearshore circulation in a tropical fringing reef system, J. Geophys. Res. Oceans., 116, doi:10.1029/2010jc006439.

Taylor, J. G., and A. F. Pearce (1999), Ningaloo Reef currents: implications for coral spawn dispersal, zooplankton and whale shark abundance, $J$. Royal Soc. Western Australia, 82, 57-65.

Thompson, R. (1987), Continental-shelf-scale model of the Leeuwin Current, J. Mar. Res., 45(4), 813-827. 
Umlauf, L., and H. Burchard (2003), A generic length-scale equation for geophysical turbulence models, J. Mar. Res., 61(2), 235-265.

Warner, J. C., C. R. Sherwood, H. G. Arango, and R. P. Signell (2005), Performance of four turbulence closure models implemented using a generic length scale method, Ocean Model., 8(1-2), 81-113.

Whitney, M. M., and J. S. Allen (2009), Coastal wind-driven circulation in the vicinity of a bank. Part I: Modeling flow over idealized symmetric banks, J. Phys. Oceanogr., 39(6), 1273-1297.

Willmott, C. J. (1981), On the validation of models, Physical Geography, 2, 184-194.

Wilson, S. G., T. Pauly, and M. G. Meekan (2002), Distribution of zooplankton inferred from hydroacoustic backscatter data in coastal waters off Ningaloo Reef, Western Australia, Mar. Freshw. Res., 53(6), 1005-1015.
Woo, M., and C. Pattiaratchi (2008), Hydrography and water masses off the Western Australian coast, Deep-Sea Res. Part I-Oceanogr. Res. Pap., 55(9), 1090-1104.

Woo, M., C. Pattiaratchi, and W. Schroeder (2006), Summer surface circulation along the Gascoyne continental shelf, Western Australia, Cont. Shelf Res., 26(1), 132-152.

Wyatt, A. S. J., R. J. Lowe, S. Humphries, and A. M. Waite (2010), Particulate nutrient fluxes over a fringing coral reef: relevant scales of phytoplankton production and mechanisms of supply, Mar. Ecol. Prog. Ser., 405, 113-130. Zamudio, L., and M. Lopez (1994), On the effect of the alongshore pressure gradient on numerical simulation over the northern California continentalshelf, J. Geophys. Res. Oceans., 99(C8), 16117-16129. 